\title{
Smad4 deficiency in T cells leads to the Th17-associated development of premalignant gastroduodenal lesions in mice
}

\author{
Jennifer Nancy Hahn, ${ }^{1}$ Vincent George Falck, ${ }^{2}$ and Frank Robert Jirik ${ }^{1}$ \\ 1Department of Biochemistry and Molecular Biology, The McCaig Institute for Bone and Joint Health, \\ and ${ }^{2}$ Department of Pathology and Laboratory Medicine, University of Calgary, Calgary, Alberta, Canada.
}

\begin{abstract}
While there is evidence that specific $T$ cell populations can promote the growth of established tumors, instances where $T$ cell activity causes neoplasms to arise de novo are infrequent. Here, we employed two conditional mutagenesis systems to delete the TGF- $\beta$ signaling pathway component Smad4 in T cells and observed the spontaneous development of massive polyps within the gastroduodenal regions of mice. The epithelial lesions contained increased levels of transcripts encoding IL-11, IL-6, TGF- $\beta$, IL-1 $\beta$, and TNF- $\alpha$, and lamina propria cells isolated from lesions contained abundant IL-17A ${ }^{+} \mathrm{CD4}^{+} \mathrm{T}$ cells. Furthermore, we found that Smad 4 deficiency attenuated TGF- $\beta$-mediated in vitro polarization of FoxP3 ${ }^{+} \mathrm{CD} 4^{+} \mathrm{T}$ cells, but not IL-17A ${ }^{+} \mathrm{CD} 4^{+} \mathrm{T}$ cells, suggesting that the epithelial lesions may have arisen as a consequence of unchecked Th17 cell activity. Proinflammatory cytokine production likely accounted for the raised levels of IL-11, a cytokine known to promote gastric epithelial cell survival and hyperplasia. Consistent with IL-11 having a pathogenic role in this model, we found evidence of Stat 3 activation in the gastric polyps. Thus, our data indicate that a chronic increase in gut Th17 cell activity can be associated with the development of premalignant lesions of the gastroduodenal region.
\end{abstract}

\section{Introduction}

The importance of TGF- $\beta$ in preventing excessive T lymphocyte activation, proliferation, and development of autoimmunity is illustrated by the striking phenotype of $\mathrm{Tg} f\left(1^{-/-}\right.$mice (1-3), as well as by mice lacking normal TGF- $\beta$ RI (4) or TGF- $\beta$ RII (5-7) T cell function $(8-10)$. Such animals develop a severe systemic inflammatory disorder leading to early lethality. However, in addition to its suppressive effects on "conventional" $\alpha / \beta$ T cell receptor $\mathrm{CD} 4^{+}$and $\mathrm{CD} 8^{+} \mathrm{T}$ cells, TGF- $\beta$, in concert with specific combinations of cytokines, can also promote the development of specific types of both pro- and antiinflammatory $\mathrm{T}$ cells, including Th17, Tc17, Tregs, and certain T suppressor (Ts) cell subsets (11-16). The Th17 subset, a population that normally resides in the lining of the gut, can also originate from activated $T$ cell populations upon exposure to specific combinations of cytokines (11). Thus, expression of ROR $\gamma t$, a key transcription factor required for Th17 cell ontogeny, is dependent on TGF- $\beta$ and IL-6 $(11,17)$, with IL-1 and IL-21 also participating in the development of these cells. In addition, macrophage-derived IL-23 participates in the maintenance of Th17 effector function (11). Targeting of the gene encoding IL-17A has demonstrated a role for this cytokine in the pathogenesis of a variety of murine disease models, primarily as a result of its ability to activate and also stimulate proinflammatory cytokine release from bone marrow-derived cells such as macrophages and granulocytes. Thus, IL-17A elicits the expression of TNF- $\alpha$, IL-1 $\beta$, IL- 6 , GM-CSF, G-CSF, chemokines, and metalloproteinases from a variety of different cell types (11).

TGF- $\beta$ mediates its biological effects via dimerization of two transmembrane receptor Ser/Thr kinases, TGF- $\beta$ RI and TGF- $\beta$ RII (9). Receptor activation leads to phosphorylation of Smad3 and/or Smad2, which together in partnership with Smad4 (a "co-Smad") translocate to the nucleus to bring about the regulation of specific

Conflict of interest: The authors have declared that no conflict of interest exists. Citation for this article: J Clin Invest. 2011;121(10):4030-4042. doi:10.1172/JCI45114. target genes (18). TGF- $\beta$ receptors can also stimulate Smad4-independent pathways, leading to the activation of mitogen-activated protein kinases, phosphatidylinositol 3-kinase, and the Rho family members RhoA and Cdc42 $(19,20)$. Interestingly, and in contrast to the severe systemic immunopathology caused by $\mathrm{T}$ cell-specific disruptions in the proximal components of the TGF- $\beta$ signaling pathway, pathology resulting from $\mathrm{T}$ cell-specific Smad4 deficiency was shown to be limited to induction of proliferative epithelial lesions of the gastrointestinal tract $(10,21)$. Thus, conditional deletion of floxed $\operatorname{Smad4}(\operatorname{Smad} 4 / / f l)$ during T cell development using either the Lck-Cre or CD4-Cre systems led to the development of gastrointestinal epithelial tumors at multiple anatomical sites in the gut, and it was suggested that Th2 cell cytokines, and notably IL-6, were involved in the pathogenesis of the gut lesions (21). While IL- 6 could be involved in tumorigenesis in specific gut regions, within the stomach it is another IL-6 family cytokine, IL-11, that has achieved notoriety as a key tumor-promoting factor in both humans and mice (22-25). In human gastric cancer, for example, IL-11 was proposed to trigger Stat 3 activation, cell proliferation, and invasiveness $(24,25)$. Also, sustained Stat 3 activation by IL- 11 was linked to gastric neoplasia in various animal models (23). For example, in the elegant $g p 130^{Y 757 F / Y 757 F}$ transgenic model of murine gastric neoplasia, the importance of IL-11 was highlighted by the discovery that tumor development was prevented by IL-11 receptor $\alpha$ (IL-11R $\alpha$ ) deficiency, but not the lack of IL-6 (22). IL-11 appears to have both an antiapoptotic and growth-promoting effect on the gut epithelium, since this cytokine is able to prevent intestinal inflammation and to promote the repair of mucosal damage (26).

With our initial plan being to investigate the consequences of Smad4 loss in $\mathrm{CD}^{+} \mathrm{T}$ cells, we interbred Smad4fl/fl mice with a line carrying a granzyme B (GB) promoter-Cre transgene, a system previously used to carry out Cre recombinase-mediated gene alterations within activated $\mathrm{CD}^{+} \mathrm{T}$ cells $(27-29)$. Interestingly, recent publications have reported that $\mathrm{CD}^{+}$cells express $\mathrm{GB}$ (although 


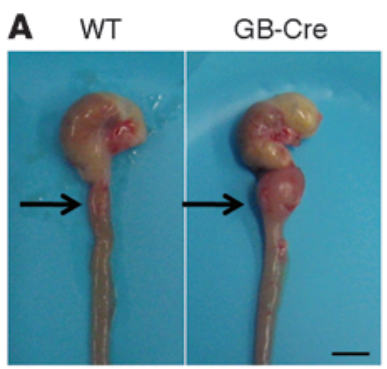

C

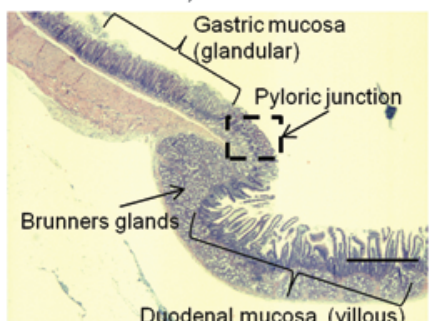

$\mathbf{F}$
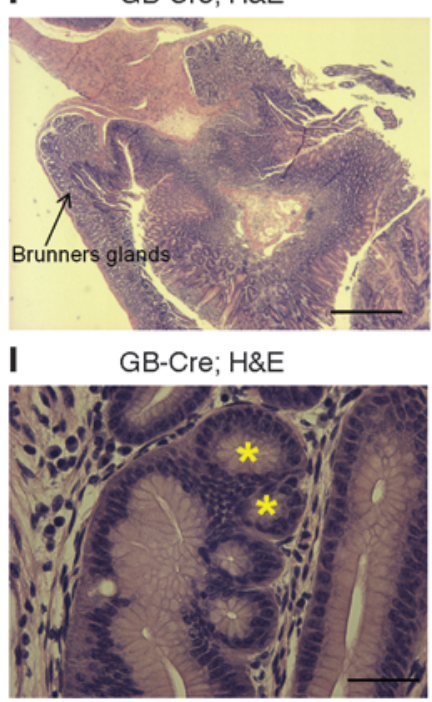

B

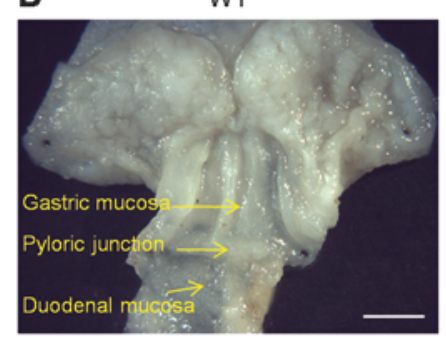

D

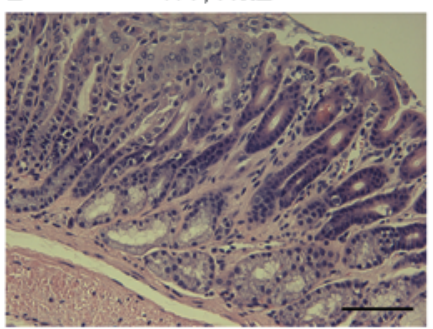

G GB-Cre; H\&E

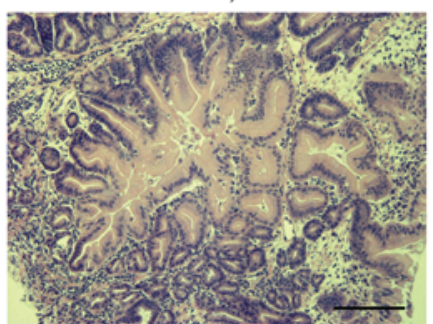

J GB-Cre; PCNA

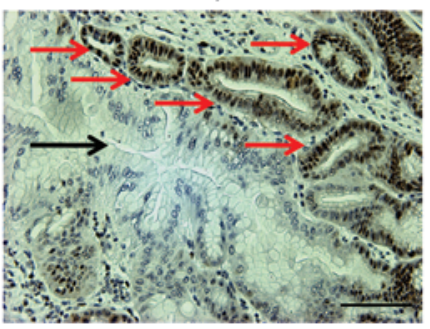

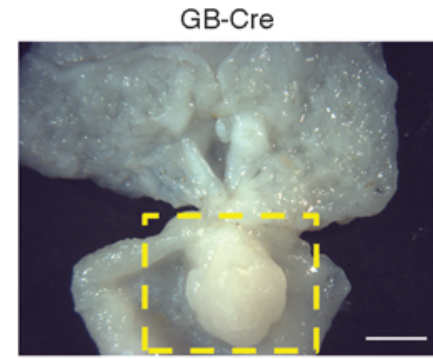

E WT; TFF1

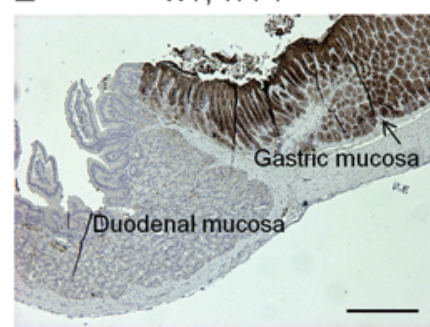

H GB-Cre; TFF1

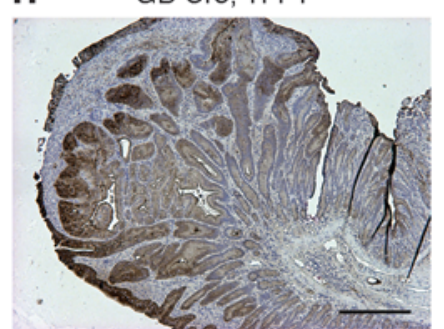

K GB-Cre; H\&E

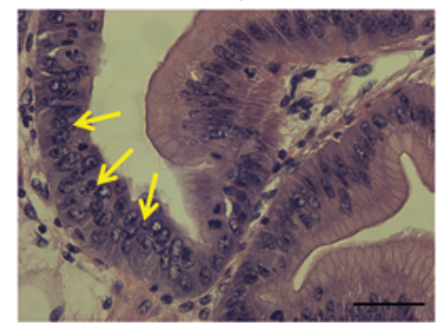

Figure 1

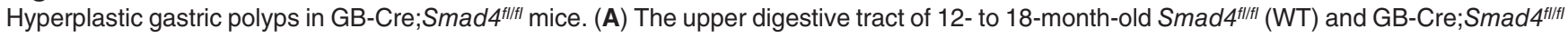
(GB-Cre) mice, with the latter showing swelling at the gastroduodenal junction (arrows). Scale bar: $0.5 \mathrm{~cm}$. (B) A representative GB-Cre antropyloric polyp (dash-lined box) and WT antro-pyloric region. Scale bars: $0.25 \mathrm{~cm}$. (C-E) Antro-pyloric region of a WT mouse showing H\&E staining and anti-TFF1 antibody reactivity (scale bars: 1,000 $\mu \mathrm{m}, 125 \mu \mathrm{m}$, and $500 \mu \mathrm{m}$, respectively). The pyloric junction (indicated by a dash-lined box in C), as well as a higher-magnification view of the antro-pyloric mucosa (D). Anti-TFF1 staining was limited to the gastric mucosa (E; arrow). (F-K) GB-Cre gastric lesion sections stained with H\&E, anti-TFF1 antibody, or anti-PCNA antibody (scale bars: 1,000 $\mu \mathrm{m}$ [F], 250 $\mu \mathrm{m}$ [G], 500 $\mu \mathrm{m}[\mathbf{H}], 40 \mu \mathrm{m}[\mathbf{I}-\mathbf{K}])$. A GB-Cre gastric polyp (F), with glands demonstrating elongation, branching, and dilation (G), as well as "side buds" (I; asterisks) containing abundant anti-PCNA antibody-reactive cells ( $\mathbf{J}$; black arrow indicates non-proliferating elongated gland; red arrows indicate proliferative side buds). Low-grade epithelial dysplasia was evident (K; arrows), as well as diffuse anti-TFF1 antibody staining of the polyp mucosa $(\mathbf{H})$. Images are representative of 4-6 mice per group.

at much lower levels) (30) and also that the suppression of target cells by activated $\mathrm{CD} 4^{+} \mathrm{CD} 25^{+}$regulatory cells (Tregs) and $\mathrm{T}$ regulatory $1(\operatorname{Tr} 1)$ cells involves substantial upregulation of GB expression (31-34). In addition, Th17 cells have also been shown to express GB $(35,36)$. Thus, we found that upon aging, there was evidence of GB-Cre-triggered Cre reporter gene expression within a substantial fraction of splenic $\mathrm{CD}^{+}$and $\mathrm{CD} 4^{+} \mathrm{T}$ cells. Interestingly, we also found that aged GB-Cre;Smad4fl/fl mice developed massive hyperplastic polyps within the antro-pyloric region of the stomach. Using a second model of T cell-specific Smad4 deficiency, Lck-Cre;Smad4 $4^{f l f l}$ mice, we observed the development of proliferative gut lesions (adenomas) in the sub-pyloric duodenum. Lamina propria cells contained increased IL-17A-expressing CD4 ${ }^{+}$ T cells, as well as abundant transcripts for various proinflammatory cytokines. Polyps also expressed abundant IL-11-encoding transcripts. Implicating a deficiency of induced Tregs (iTregs) as a potential contributing factor in the genesis of the gastroduodenal pathology seen in the two models, we found that in vitro 

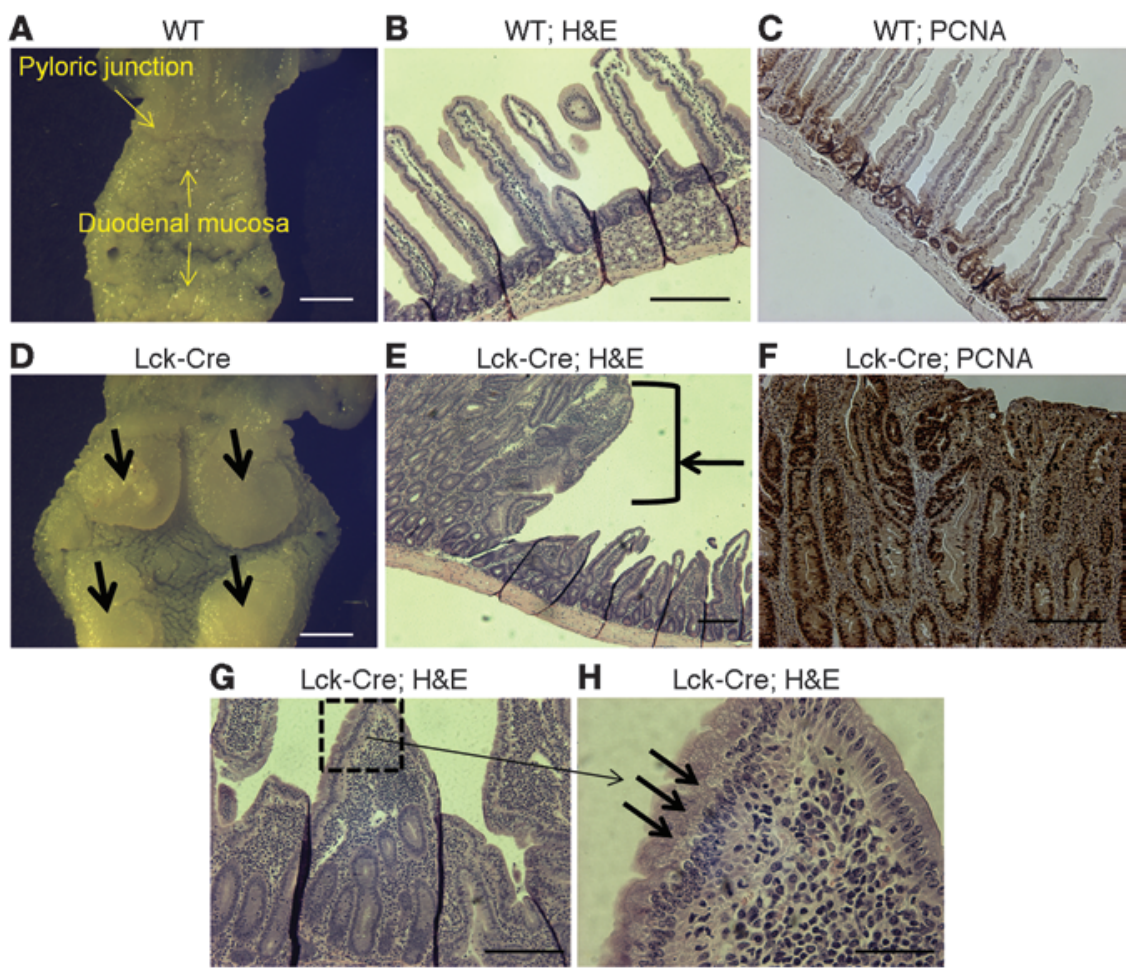

H Lck-Cre; H\&E

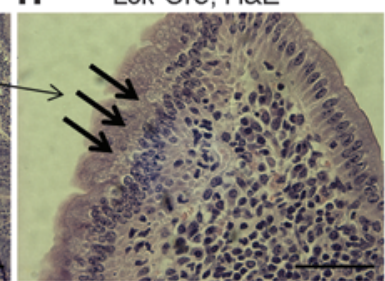

\section{Figure 2}

Lck-Cre;Smad4 $4^{\text {fl/fl }}$ mice develop proximal duodenal adenomas. (A-C) Proximal duodenal region of a 12-month-old WT (Smad $\left.4^{f / f t}\right)$ mouse (A, scale bar: $0.25 \mathrm{~cm}$ ) showing normal arrangement of villi (B), and anti-PCNA antibody staining limited to the basal region of villous crypts (C) (scale bars: $250 \mu \mathrm{m}$ ). (D-H) Representative duodenal adenomas in a 12-month-old LckCre;Smad4 ${ }^{f l / f l}$ (Lck-Cre) mouse (D; arrows), located immediately distal to the pyloric junction (scale bar: $0.25 \mathrm{~cm}$ ). The lesions showed elongated distended villi with a crowded glandular architecture (E; bracket) (scale bar: 250 $\mu \mathrm{m})$, evidence of hematopoietic cell infiltrates (G) (scale bar: $250 \mu \mathrm{m}$ ), and areas of epithelial dysplasia (H, arrows) exhibiting a crowded and abnormal arrangement of nuclei (scale bar: $60 \mu \mathrm{m}$ ). (F) A representative section from an adenoma showing diffuse anti-PCNA antibody staining (scale bar: $250 \mu \mathrm{m}$ ). Images are a representative of 4 control and 4 experimental mice.
FoxP3 $^{+}$polarization was compromised in Smad4-deficient T cells. Our findings suggested that loss of Smad 4 in T cells leads to augmented gut Th17 activity that is associated with the development of premalignant lesions of the murine gastroduodenal mucosa.

\section{Results}

GB-Cre;Smad4fl/fl mice develop gastric hyperplastic polyps. At 12-18 months of age, GB-Cre;Smad4flfl mice (mixed C57BL/6, FVB, Black Swiss, 129 background) developed weight loss and lethargy, requiring euthanasia (Supplemental Figure 1, A and B; supplemental material available online with this article; doi:10.1172/ JCI45114DS1). These mice exhibited large polyps of the antropyloric region (Figure 1, A and B), as well as severe anemia (Supplemental Figure 1C). Fecal occult blood was present in all the experimental animals (data not shown), indicating that the anemia was most likely due to chronic blood loss. Younger animals ( $\sim 25$ weeks of age) exhibited one or more small nodules in the pyloric canal (Supplemental Figure 1D). Histological comparison of the antropyloric regions of control (Figure 1, C and D) and GB-Cre;Smad $4 / / f l$ mice revealed that the latter contained large, polypoid glandular masses (Figure 1, F and G) with elongated, branched, and dilated glands (Figure 1G) and proliferative side buds (Figure 1I) as shown by immunohistochemistry using an antibody against proliferating cell nuclear antigen (PCNA) (Figure 1J). In addition, many regions contained mitotic figures and crowded, immature cells with nuclear hyperchromasia (Figure $1 \mathrm{~K}$ ), consistent with low-grade dysplasia. The stroma of the polyps showed modestly increased lymphocytes and plasma cells, thus failing to fulfill the criteria for human juvenile polyposis, where stromal overgrowth is prominent (37). The histopathology of the polyps was most reminiscent of human gastric hyperplastic polyps (37). Trefoil factor 1 (TFF1), a gastric epithelial marker (Figure 1E), was expressed throughout the polyp epithelium (Figure $1 \mathrm{H}$ ). There were no lesions elsewhere in the gut of GB-Cre;Smad4/lfl mice. Since Lck-Cre-mediated deletions of Smad4 had been reported to lead to neoplasms at multiple sites in the gut (21), we also established an Lck-Cre;Smad4 $f^{f / f l} \mathrm{col}$ ony (C57BL/ 6 background). Interestingly, and in contrast to the previous report, we found that approximately 12-to 18-month-old Lck-Cre;Smad $4 f^{f l / l}$ mice in our colony only developed infra-pyloric duodenal adenomas (Figure 2). These duodenal lesions were characterized by elongated and distended villi with crowded glandular architecture (Figure 2E, bracket), lamina propria hematopoietic cell infiltrates (Figure 2G), dysplasia (Figure $2 \mathrm{H}$, arrows), and diffuse anti-PCNA staining consistent with epithelial hyperplasia (Figure 2F). In control duodenal samples, the anti-PCNA-positive cells were confined to the villous bases (Figure 2C).

GB-Cre-mediated Cre reporter gene excisions do not occur in polyp epithelial cells. SMAD4 and Smad4 loss has been implicated in the genesis of human (38-40) and murine $(21,41-46)$ cancers, respectively, as well as in human juvenile polyposis $(47,48)$. It was thus important to exclude the possibility that GB-Cre recombinase activity was present in the hyperplastic epithelium of the gut lesions. Thus, GB-Cre mice and GB-Cre;Smad4f/fll mice were interbred with mice carrying a Rosa26-enhanced yellow fluorescent protein reporter (R26R-EYFP) system (provided by F. Costantini, Columbia University, New York, New York, USA) (49). Examination of the gastroduodenal junctions of GB-Cre;Smad $4^{f l / f l} ; \mathrm{R} 26 \mathrm{R}-\mathrm{EYFP}$ mice revealed that EYFP expression was confined to intraepithelial and lamina propria hematopoietic cells, but was not present within either the normal lining or the polyp epithelium (Figure 3A).

The GB-Cre mouse model has been used for gene alterations in activated $\mathrm{CD}^{+} \mathrm{T}$ cells of young animals; however, analysis of GB-Cre-mediated reporter activation in hematopoietic cells of 12-month-old mice revealed a broader cellular spectrum and increased percentage of cells expressing EYFP, consistent with an age-dependent "leakiness" of this Cre system. For example, splenic 

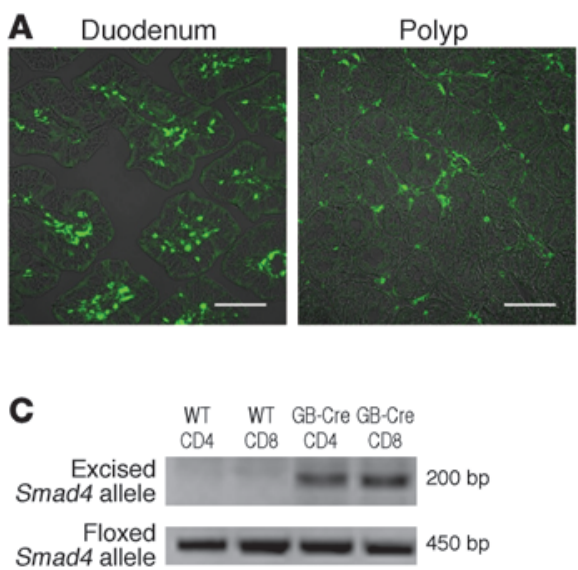

D
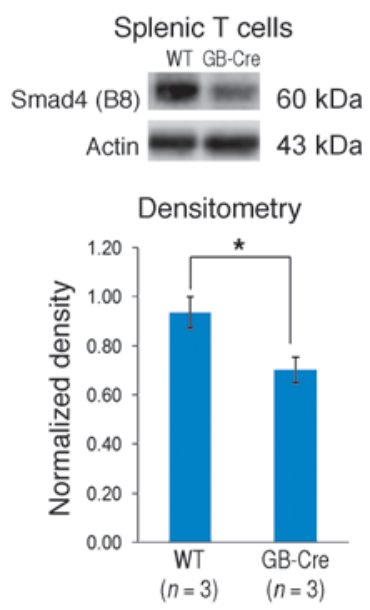

B

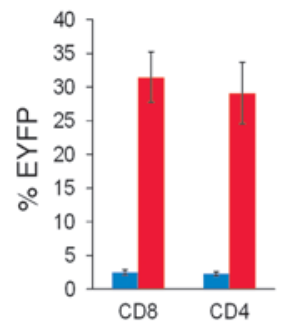

- GB-Cre;R26R-EYFP (7 wk, $n=4)$

- GB-Cre;R26R-EYFP (56-60 wk, $n=4)$

\section{E} after activation and expansion

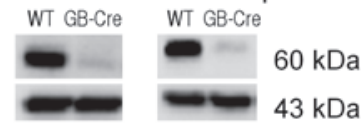

Densitometry

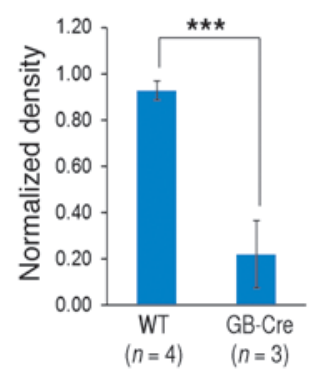

\section{Figure 3}

Characterization of GB-Cre-mediated Cre reporter gene activation. (A) Anti-EYFP antibody staining of a representative (of 3 mice) region of duodenum and the antro-pyloric polyp of an 18-month-old GB-Cre;Smad4fl/fl;R26R-EYFP mouse. EYFP immunostaining was present in lamina propria and intraepithelial inflammatory cells; however, the epithelium was negative for reporter gene expression (scale bars: $250 \mu \mathrm{m}$ ). (B) Flow cytometric detection of EYFP expression in 7-week and 56- to 60-week-old GB-Cre;R26R-EYFP splenocytes stained with antiCD4 and anti-CD8 antibodies (data are shown as the mean $\pm \mathrm{SEM} ; n=4$ mice/group). Representative flow cytometry plots are shown in Supplemental Figure 2A. (C) Excision of Smad4 analyzed by PCR in 12- to 18month-old Smad4 ${ }^{f / I f l}$ (WT) and GB-Cre;Smad4 $4^{\text {fllfI }}$ (GBCre) $\mathrm{CD}^{+}$or $\mathrm{CD}^{+}$splenocytes (representative of 3 mice). (D) Immunoblotting of splenic T cells isolated from 12- to 18-month-old Smad4 ${ }^{f / / f l}$ and experimental (GB-Cre;Smad4t/fil) mice for Smad4 expression levels, along with densitometry results (data shown are the mean \pm SEM; $n=3$ mice/group). (E) Immunoblotting for Smad4 expression in lysates from GB-Cre;Smad $4^{\text {t//fI }}$ and Lck-Cre;Smad4 fl/fl (Lck-Cre) splenic T cells following anti-CD3-mediated activation and expansion in IL-2 for 7-9 days, with densitometry (data are shown as the mean \pm SEM; $n=3-4$ mice/group). ${ }^{*} P<0.05$, ${ }^{* * *} P<0.001$, 2-tailed unpaired $t$ test.
T lymphocyte excisions in GB-Cre;R26R-EYFP mice increased from less than $5 \%$ at approximately 7 weeks to about $30 \%$ by approximately 12 months of age (Figure 3B and Supplemental Figure 2A). Interestingly, comparable age-dependent increases in $\mathrm{EYFP}^{+}$cells were also observed in splenic and bone marrow CD11 $\mathrm{b}^{+}$and CD19+ cell populations (data not shown), raising the possibility of low-level GB-Cre activity leading to accumulation of floxed gene excisions over time within progenitor populations. Furthermore, demonstrating that Smad4 excisions had no impact on the frequency of subsequent spontaneous GB-Cre-mediated excisions (EYFP ${ }^{+}$activation) in splenic cells, we found comparable frequencies of $\mathrm{EYFP}^{+}$cells in the splenocytes of GB-Cre;Smad4//fl; R26R-EYFP mice (data not shown). In view of the ability of TGF- $\beta$ to downregulate GB expression in $\mathrm{CD}^{+} \mathrm{T}$ cells (50), it was theoretically possible that regional differences in TGF- $\beta$ concentrations available to cells in vivo may have contributed to the relative inefficiency of the GB-Cre model (assuming that TGF- $\beta$ response elements were preserved within the relatively short GB promoter fragment used in the GB-Cre transgenic line). In contrast to the GB-Cre system, the Lck-Cre system (51) resulted in the activation of the EYFP Cre reporter in nearly $100 \%$ of thymocytes and peripheral T cells (data not shown).

Cre-mediated excision of floxed Smad4 alleles in GB-Cre;Smad $4^{f / f l}$ splenic $\mathrm{CD}^{+}$and $\mathrm{CD}^{+}$cells (Figure $3 \mathrm{C}$ ) was demonstrated by PCR, and immunoblot detection of Smad4 protein in lysates prepared from purified splenic $\mathrm{T}$ cells revealed an approximately $30 \%$ decrease in this protein in aged experimental animals (Figure 3D), consistent with our findings using the EYFP-based Cre reporter system (Figure 3B). Importantly, immunoblotting experiments on either GB-Cre;Smad4//fl or Lck-Cre;Smad4fl/fl (the "positive control" for Smad4 gene deletion) splenic T cells that had been anti-CD3 antibody-activated and expanded in culture demonstrated that Smad4 protein was virtually undetectable in both groups (Figure 3E) as compared with the wildtype controls. Flow cytometry of the expanded splenic T cells illustrated that the live cell population consisted exclusively of approximately equal proportions of both $\mathrm{CD}^{+}$and $\mathrm{CD}^{+} \mathrm{T}$ cells (data not shown), showing that floxed Smad4 excisions were occurring in both populations. Thus, in contrast to the results obtained using freshly explanted $T$ cells, these results demonstrated that GB-Cre-mediated excisions in activated $T$ cell populations were very efficient.

Since loss of Smad4 expression could potentially promote gastric neoplasia, it was important to demonstrate that Smad4 protein expression was intact within the epithelial component of the gut lesions. Therefore, using immunohistochemistry, we assessed Smad4 expression within the epithelium of the antro-pyloric and proximal duodenal regions of control mice and polyps that were derived from GB-Cre;Smad4//fl and Lck-Cre;Smad4l/fll mice (Supplemental Figure 2, $\mathrm{B}$ and $\mathrm{C}$ ). We found that Smad4 was expressed throughout the highly proliferative (Figure 2F), dysplastic epithelium in the Lck-Cre;Smad $4^{l / f l}$ duodenal adenomas (Supplemental Figure 2C). Likewise, both the control gastric epithelium and the antral polyps of GB-Cre;Smad $4 / / f l$ mice showed Smad4 expression in mucosal regions where cell proliferation (PCNA-positive cells) was occurring (Supplemental Figure 



D

G1 G2 G3 W1 W2 W3

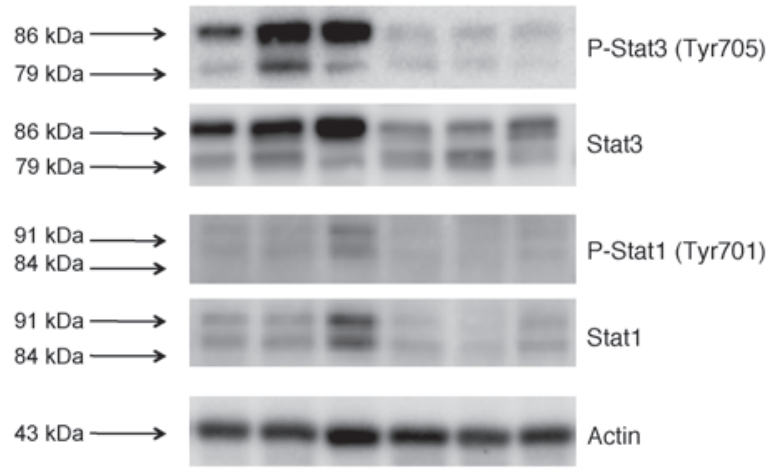

W1 to $\mathrm{W} 3=\mathrm{Smad}^{\text {min }}$

G1 to G3 = GB-Cre; Smad4 $4^{\text {th }}$

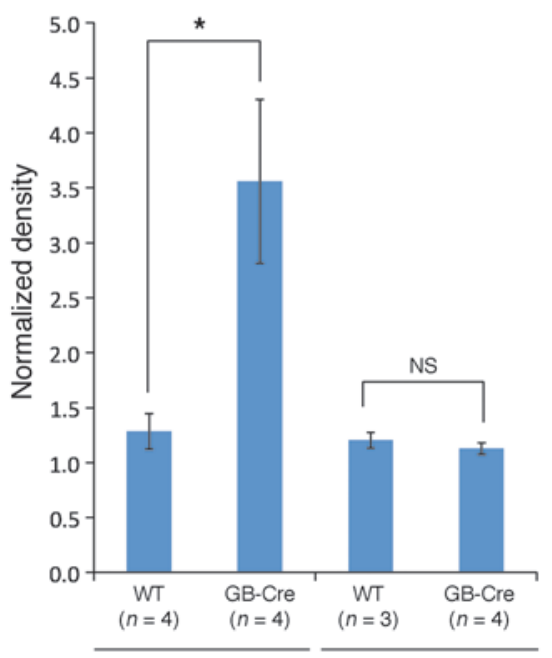

P-Stat3

P-Stat1

\section{Figure 4}

Expression of two IL-6 family cytokines and evidence of Stat3 activation in GB-Cre;Smad4t/flil antro-pyloric polyps. (A and C) Quantitative RT-PCR (qRT-PCR) real-time analysis of the cytokine transcripts from the antro-pyloric regions of 12- to 18-month-old Smad4 $4^{f / f l}$ (WT), and polyp-containing GB-Cre;Smad4t/ffl (GB-Cre) mice. Data are depicted as the mean \pm SEM ( $n=4-5$ mice/group). (B) qRT-PCR real-time analysis of cytokine transcripts from the proximal duodenum region of 12- to 18-month-old Smad4fl/fl and Lck-Cre;Smad4t/flil (Lck-Cre) mice. Data are shown as the mean \pm SEM ( $n=4$ mice/group). Act $\beta A$ and Act $\beta B$, activin subunits $\beta A$ and $\beta B$, respectively. (D) Immunoblotting of lysates prepared from the antro-pyloric region of 12- to 18-month-old control (WT) and polyp-containing GB-Cre;Smad4t/fll mice, showing the expression levels of Stat3, phospho-Stat3, Stat1, and phospho-Stat1 proteins, with densitometry for phospho-Stat3 being normalized to Stat3 levels and phospho-Stat1 normalized to Stat1 levels. Data are shown as the mean $\pm \operatorname{SEM}\left(n=3-4\right.$ mice/group). ${ }^{\star} P<0.05,{ }^{* \star} P<0.01,{ }^{* \star *} P<0.001,2$-tailed unpaired $t$ test.

2B). As in the non-proliferative (PCNA-negative) regions of glands in the normal gastric mucosa, there were PCNA-negative glands in the polyps that did not show detectable Smad4 expression (Supplemental Figure 2B). This latter result was consistent with a previous study demonstrating the presence of Smad4 in the glandular, but not foveolar, compartment of the gastric glands (52). These results thus demonstrated that the hyperplastic epithelial cells of both models retained expression of Smad4 protein and that expression of Smad4 was highest in the proliferative (PCNA-positive) regions of both the normal and the hyperplastic epithelium. 
Transcripts encoding IL-6 family cytokines and phospho-Stat3 levels were increased in GB-Cre;Smad4flffl polyps. To gain insight into potential factors involved in polyp development, we studied IL-11 and Stat3, molecules previously shown to be important for the genesis of both murine and human gastric cancers (22-25). By real-time RT-PCR, GB-Cre;Smad4fl/fl polyp RNA samples showed dramatic increases in Il11 ( 50-fold) and Il6 ( 40-fold) transcripts (Figure 4A). Il11, but not $I l 6$, transcript levels were also significantly elevated in the adenomas of Lck-Cre;Smad $4^{f / f l}$ mice (Figure 4B). IL-6 serum levels were modestly increased in both 12- and 18-month old GB-Cre;Smad4//fl and Lck-Cre;Smad $4^{\ell / f l}$ animals as compared with control mice (Supplemental Figure 3A). Increased serum IL-6 had been previously reported in Lck-Cre;Smad4fl/fl animals (21). The levels of serum IL-6 suggested that systemic inflammation was not a prominent feature of either of the models studied herein. Gastroduodenal region cytokine transcripts were also quantified in 20- to 26-week-old GB-Cre;Smad4 $f^{l / f l}$ and Lck-Cre;Smad $4^{f l / f l}$ animals. This showed that transcripts encoding IL-11 (but not IL- 6 or IL-1 $\beta$ ) were variably increased (Supplemental Figure 3, B and C). The latter raised the possibility that IL-11 was more important to polyp pathogenesis than IL-6, at least at the earliest stages of polyp development.

Other cytokine transcripts that were elevated in the GBCre;Smad $4 f l f l$ polyps of aged mice included Il1b, Tnfa, and Tgfb (Figure 4C). High activin levels were shown to inhibit the differentiation of various gastric epithelial lineages (53); therefore, transcripts encoding alternate TGF- $\beta$ family members were examined. We found that activin subunits $\beta \mathrm{B}$ and $\beta \mathrm{A}$ were elevated in the polyps of GB-Cre;Smad4fl/fl mice (Figure 4C), while BMP2, -4, and -7 were not increased (data not shown). It was thus possible that activins were contributing to the hyperplastic process that caused polyp formation.

Neither Runx3 nor Tff1 transcript levels, known gastric tumor suppressors $(54,55)$, were altered within the polyps of GBCre; $S$ mad $4 f l f l$ mice; however, gastrin-encoding transcript levels were significantly diminished (Figure 4C). This was consistent with the finding that gastrin-deficient mice developed antral gastric tumors (56) and also with the antral gastric tumor development in the $g p 130^{Y 757 F / Y 757 F}$ model that was accompanied by reduced gastrin levels (57).

Both IL- 6 and IL-11 cause activation of Stat 3 and Stat 1 , leading to the transcription of various target genes $(22,23)$. We found that transcripts encoding MMP-13 (induced by phospho-Stat3), as well as clusterin and gremlin (IL-11 targets), previously shown to be induced in the gastric mucosa by IL-11 $(22,23)$, were significantly upregulated in GB-Cre;Smad $4^{f / f l}$ polyps (Supplemental Figure 3D). Likely consistent with an effect of IL-11, both Stat 3 and phosphoStat 3 protein levels were elevated in the polyps (Figure 4D). Stat3 protein levels were increased, perhaps owing to the ability of phospho-Stat 3 to stimulate the transcription of its own gene (58). Since epithelium accounts for the majority of the cells within a polyp, the phospho-Stat3 we detected was likely reflective of this cell population. No increases were found in levels of either Stat 1 and phospho-Stat 1 protein (Figure 4D) or the phospho-Stat 1 target gene Ip10 (Supplemental Figure 3D), suggesting that Stat 3 activation was important to GB-Cre;Smad4/f/fl polyp development.

Increased IL-17 $A^{+} C D 4^{+}$Tcells in polyp lamina propria cell populations. To characterize polyp infiltrates, we isolated lamina propria cells from GB-Cre;Smad4 $4^{l / f l}$ polyps and the antro-pyloric regions of Smad $4 f^{f / f l}$ controls. Antro-pyloric weights, as well as the absolute number of lamina propria cells, were increased owing to the large mass of the polyps (Supplemental Figure 4, A and B). The percentage of "lymphocyte-gated" cells in these isolations, however, was the same in the two groups (Supplemental Figure 4D). Flow cytometry of lymphocyte-gated populations (Supplemental Figure 4C) revealed no differences in the percentages of $\mathrm{CD}^{+}$and $\mathrm{CD}^{+} \mathrm{T}$ cells between the experimental and control mice (Figure 5A), although the absolute number of lymphocytes isolated from the polyps was increased approximately 3 -fold. The percentage of CD $11 \mathrm{~b}^{+}$cells in the GB-Cre;Smad4fl/fl polyps, however, was significantly increased (Figure 5A). Real-time RT-PCR analysis of GB-Cre;Smad4fl/fl polyp lamina propria cells revealed elevations in transcripts encoding IL-17A and IL-23p19 (Figure 5B). Importantly, intracellular cytokine staining and flow cytometry of lamina propria cells demonstrated that IL-17A ${ }^{+} \mathrm{CD} 4^{+}$ cells were the only source of the IL-17A protein. Also, compared with controls, this subset was approximately 7 -fold more abundant within GB-Cre;Smad4l/fl polyp lamina propria cell populations (Figure 5, C-E). Tnfa and Il1 b were also elevated in the GB-Cre;Smad4//fl samples (Figure 5B). Since Ifng and Il4 levels were not increased, the results demonstrate that Th17 cells were the predominant $T$ cell subset within the polyps. Similar to the GB-Cre;Smad4flfl lesions, LckCre;Smad $4 / / f l$ duodenal adenoma lamina propria cells demonstrated increased levels of transcripts encoding IL-17A, IL-23p19, and TNF- $\alpha$ (Figure 5F). As with the GB-Cre;Smad4f/fll lamina propria cells, no significant increases in Ifng or Il4 were seen in the Lck-Cre;Smad $4 f^{f / f l}$ lesions, and no increase in Foxp3 transcript levels were observed (Figure 5, B and F). Thus, the presence of a Th17-dominated inflammatory response characterized the polyps of both models.

Smad4 deficiency impairs in vitro polarization of Fox $\mathrm{P3}^{+} \mathrm{T}$ cells. Since TGF- $\beta$ is required for both Th17 and iTreg generation, we next determined whether Smad4 deficiency would alter the in vitro development of either IL- $17 \mathrm{~A}^{+}$or FoxP $3^{+} \mathrm{CD}^{+} \mathrm{T}$ cells. For this $\mathrm{T}$ cell polarization study, the Lck-Cre system was used, since, unlike the GB-Cre system, this model results in Smad4 deletions in approximately $100 \%$ of naive T cells (51). Thus, total splenic T cells and naive splenic T cells obtained from wild-type or Lck-Cre;Smad 4 fl/fl mice were activated under non-polarizing, iTreg-polarizing, or Th17-polarizing conditions. These experiments revealed a striking inhibition of FoxP3 ${ }^{+} \mathrm{CD}^{+} \mathrm{T}$ cell development when Smad4-deficient splenic $T$ cells were subjected to activation under iTreg-polarizing conditions (Figure 6A). Since splenic T cells are composed of a mixture of naive, effector, and memory $\mathrm{T}$ cell populations, we also carried out iTreg polarizations of purified naive Smad4-deficient $\mathrm{T}$ cells. The naive $\mathrm{T}$ cells also demonstrated a significant impairment in $\mathrm{FoxP}^{+}$polarization (Figure 6B). This was consistent with the previously described partial defect in iTreg polarization of CD4Cre;Smad4 $4^{f l / f l}$ naive T cells (59). In contrast, IL-17A+CD4+ $\mathrm{T}$ cell generation under Th17-polarizing conditions was unaffected by the loss of Smad4 in either total splenic T cells (data not shown) or naive T cells (Figure 6C). In summary, although TGF- $\beta$ is required for both Th17 and iTreg development, the arm of the TGF- $\beta$ signal transduction pathway involving Smad4 appears to be essential only for normal FoxP3 ${ }^{+}$expression by polarized $\mathrm{T}$ cells.

Can IL-17A stimulate IL-11 expression from gastric explants or stromal cells? We next set out to determine whether IL-17A would be able to stimulate IL-11 expression from gastric tissues or stromal cells. Tissue samples excised from the antro-pyloric regions of young wild-type animals were cultivated in the presence of IL-17A for 24 hours. However, real-time RT-PCR of gastric explant RNA revealed no increase in Il11 expression in the IL-17A-treated samples, while transcript levels of the related cytokine Il6 exhibited an upward trend (Figure 7A). 

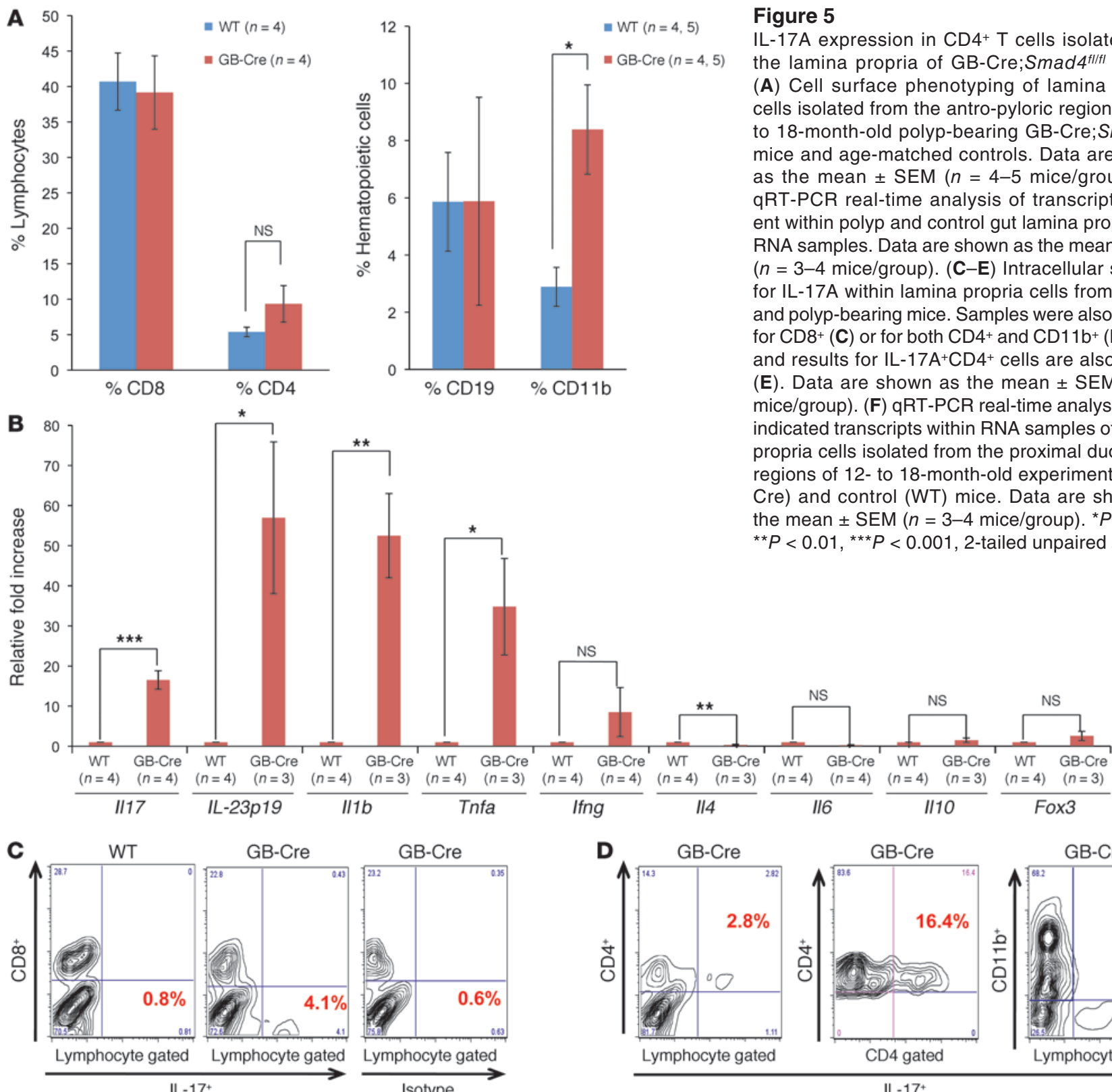

Isotype

$\mathbf{F}$

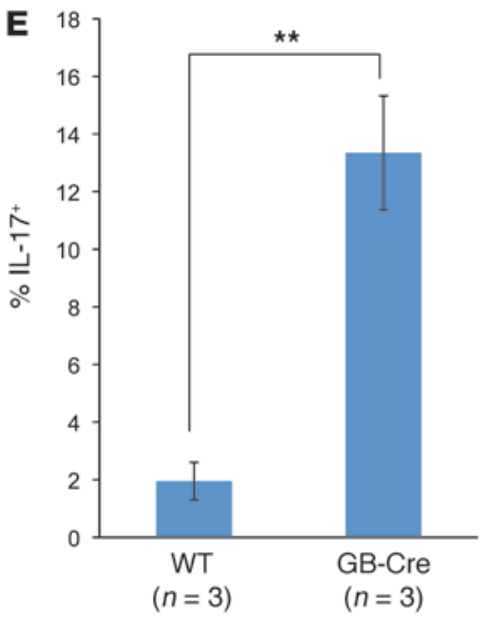

\section{Figure 5}

IL-17A expression in CD4+ $T$ cells isolated from the lamina propria of GB-Cre;Smad4t/ltt polyps. (A) Cell surface phenotyping of lamina propria cells isolated from the antro-pyloric regions of 12 to 18 -month-old polyp-bearing GB-Cre;Smad4t/ltt mice and age-matched controls. Data are shown as the mean \pm SEM ( $n=4-5$ mice $/$ group). (B) qRT-PCR real-time analysis of transcripts present within polyp and control gut lamina propria cell RNA samples. Data are shown as the mean \pm SEM ( $n=3-4$ mice/group). (C-E) Intracellular staining for IL-17A within lamina propria cells from control and polyp-bearing mice. Samples were also stained for $\mathrm{CD}^{+}(\mathbf{C})$ or for both $\mathrm{CD} 4^{+}$and $\mathrm{CD} 11 \mathrm{~b}^{+}$(D) cells, and results for IL-17A ${ }^{+} \mathrm{CD} 44^{+}$cells are also shown (E). Data are shown as the mean \pm SEM $(n=3$ mice/group). (F) qRT-PCR real-time analysis of the indicated transcripts within RNA samples of lamina propria cells isolated from the proximal duodenum regions of 12- to 18-month-old experimental (LckCre) and control (WT) mice. Data are shown as the mean \pm SEM ( $n=3-4$ mice/group). ${ }^{*} P<0.05$, ${ }^{* \star} P<0.01,{ }^{* \star *} P<0.001,2$-tailed unpaired $t$ test.

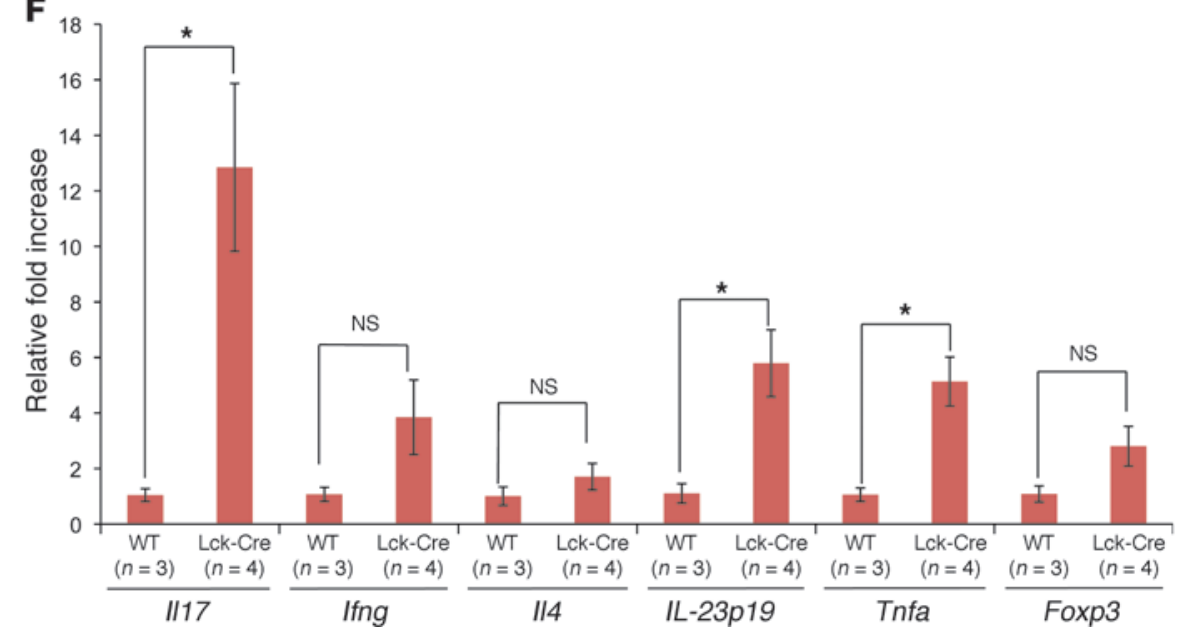


A

WT

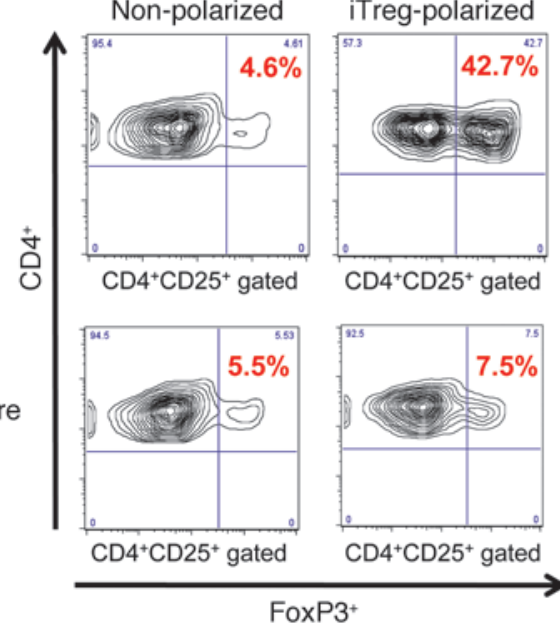

B

WT

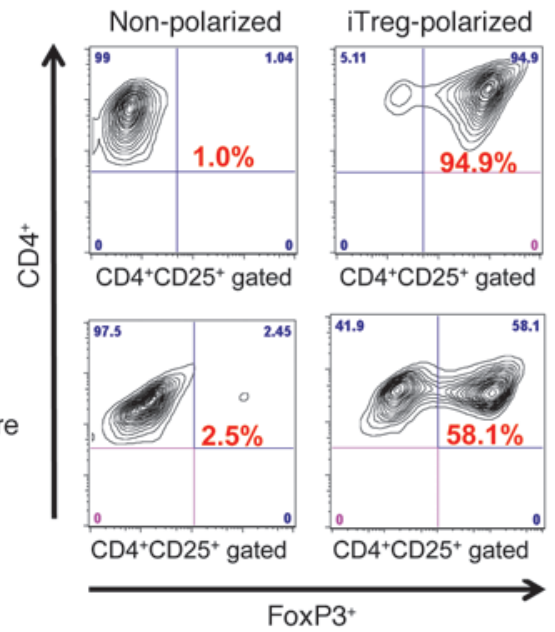

C

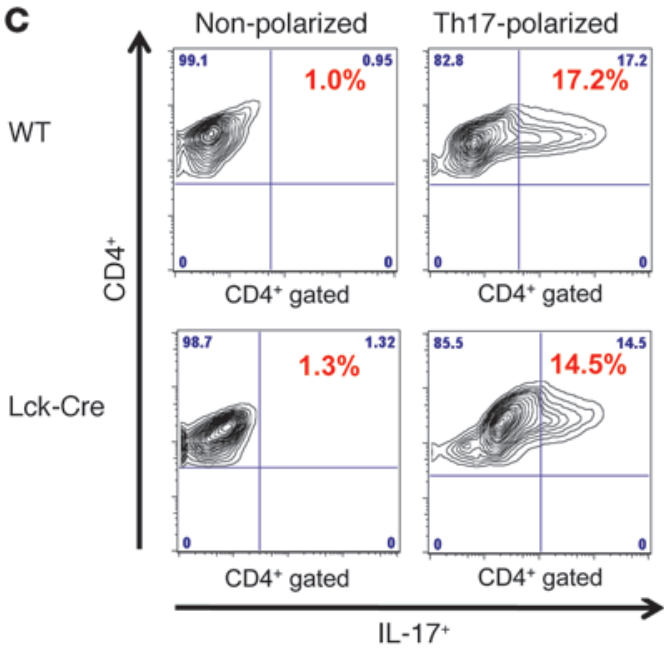

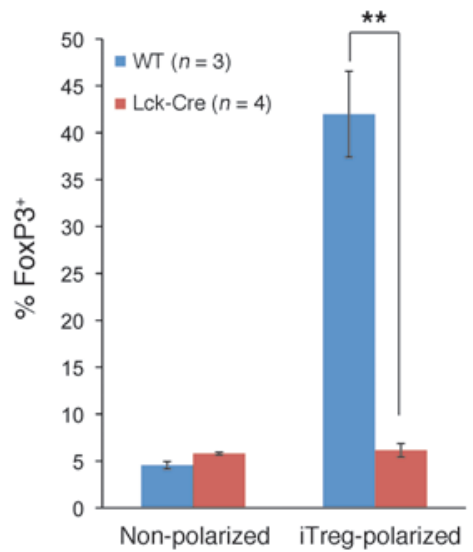
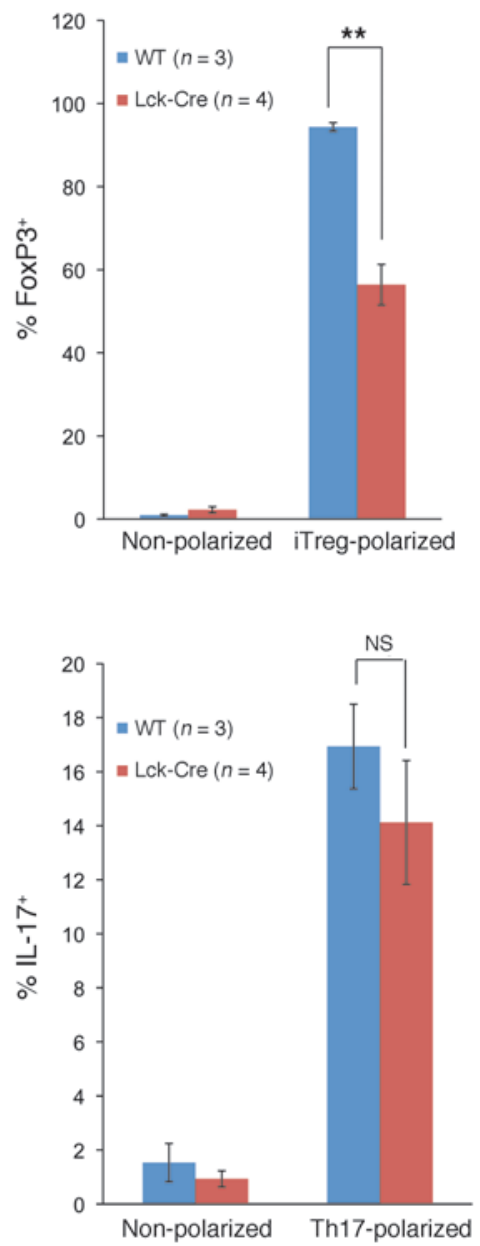

Figure 6

Smad4 deficiency impairs iTreg polarization. Splenic T cells from control (WT) and Smad4deficient (Lck-Cre) mice were activated under non-polarizing (using plate-bound anti-CD3, anti-CD28) or iTreg-polarizing conditions (A). Naive T cells isolated from splenocytes from control (WT) and Smad4-deficient (LckCre) mice were similarly activated under non-polarizing, iTreg-polarizing (B), or Th17polarizing $(\mathbf{C})$ conditions. FoxP3 ${ }^{+}(\mathbf{A}$ and $\mathbf{B})$ or $\mathrm{IL}-17^{+}$(C) expression was detected by intracellular cytokine staining and flow cytometry. Average results indicating the numbers of $\mathrm{CD}^{+} \mathrm{T}$ cells that were Foxp3 $3^{+}(\mathbf{A}$ and $\mathbf{B})$ or

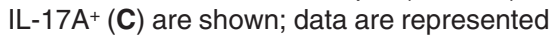
as the mean \pm SEM ( $n=3-4$ mice/group). ${ }^{* *} P<0.01$, 2-tailed unpaired $t$ test.

inductions of transcripts encoding IL-11, no significant increases in IL-11-encoding transcripts were seen in IL-17A-stimulated M2-10B4 cells, and only a modest induction of IL-11-encoding transcripts was detected in the D1 cell line (Figure 7B). IL-6 levels were significantly elevated in the stromal cells by IL-17A stimulation (Figure $7 \mathrm{~B}$ ) as previously reported (61). Thus, if IL-17A was responsible for the striking increases in IL-11-encoding transcripts observed in GB-Cre;Smad4//fl] polyps, it was likely acting via an indirect mechanism. For example, IL-17A stimulates macrophage production of IL- $1 \beta$, TNF- $\alpha$, and TGF- $\beta 1$, factors that are known to induce IL-11 from mesenchymal cells (62).

\section{Discussion}

The long latency of gastric polyp formation in GB-Cre;Smad4//fl mice raised the possibility that chronic exposure to an environmentally derived antigen might be involved in disease pathogenesis. For inflammatory bowel disease to occur, for example, the presence of commensal colonic flora is essential (63-65), and there is evidence that microbial flora determines gut mucosal immune responses via the regulation of Th17 and Treg populations (66-69). Intriguingly, PCR genotyping and sequence analysis of a portion of the $16 \mathrm{~S}$ rRNA gene revealed the presence of Helicobacter apodemus in antro-pyloric DNA samples of our mouse colonies (data not shown). This organism was previously shown to be

Since bone marrow stromal cells are a known source of IL-11 (60), a murine bone marrow-derived stromal cell line (M2-10B4) that is capable of supporting hematopoiesis and a stromal cell line (D1) having mesenchymal stem cell-like properties, were stimulated with either IL-17A or TGF- $\beta 1$, the latter being a factor that induces IL-11 expression. While TGF- $\beta 1$ stimulation led to strong capable of colonizing the low-pH environment of the stomach and has also been associated with gastritis $(70,71)$. In support of a role for environmental factors, a previous study using Lck-Cre;Smad $4^{f / f l}$ mice reported the development of tumors at multiple sites in the gut (21). In contrast, our Lck-Cre;Smad $4^{f / f l}$ mouse colony only developed lesions at a single site, the sub-pyloric duodenum. Given that the 
A

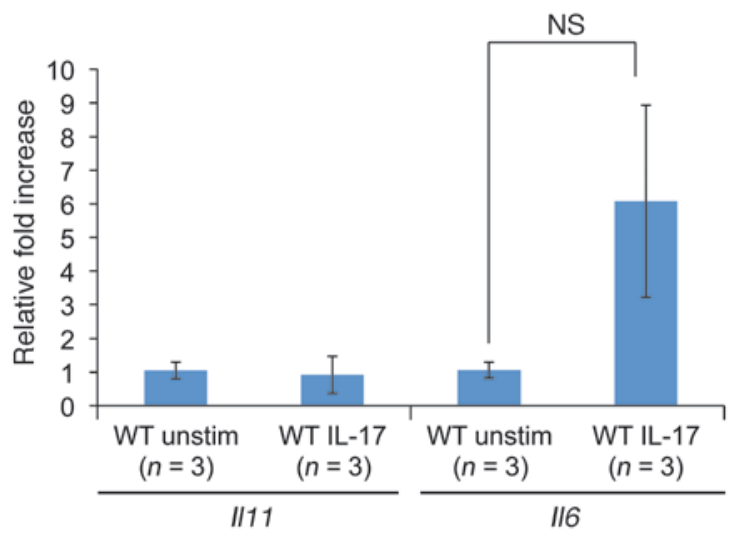

B

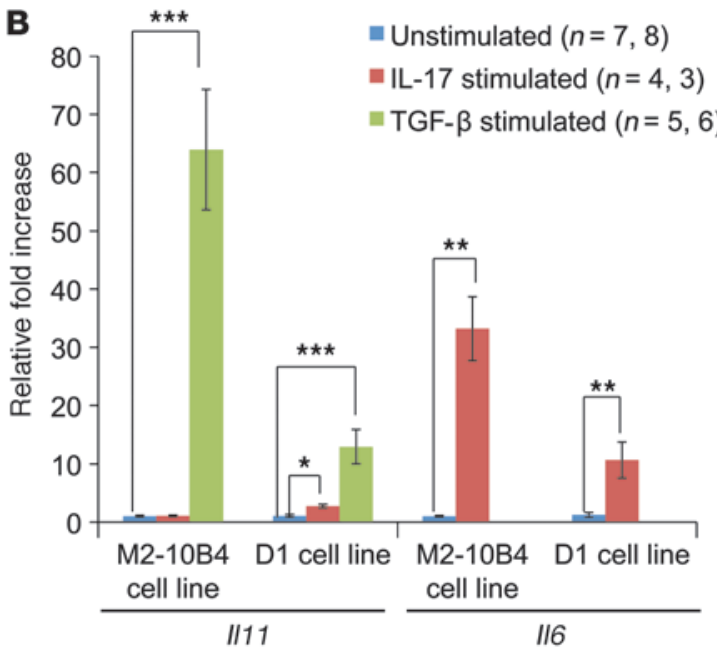

Figure 7

IL-17A stimulation of gastric explants and stromal cell lines. (A) qRT-PCR real-time analysis of the indicated transcripts of explanted tissue samples from the antro-pyloric regions of wild-type mice, cultured in either the presence or absence (unstim) of IL-17A. Data are the mean \pm SEM ( $n=3$ mice/group). (B) qRT-PCR real-time analysis of $/ / 11$ and $/ / 6$ transcripts in M2-10B4 and D1 murine bone marrow stromal cell line RNA in response to IL-17A stimulation $(n=4-3)$. As a positive control, TGF- $\beta$ stimulation $(n=5-6)$ was used. Data are the mean \pm SEM. ${ }^{\star} P<0.05,{ }^{* \star} P<0.01,{ }^{* \star} P<0.001,2$-tailed unpaired $t$ test.

same Lck-Cre model was used, the discordance between the findings by the two laboratories are likely attributable to environmental (e.g., microbiotal) factors. However, differences in genetic backgrounds of the mice remain a formal possibility, since, unlike in the previous study, where mice of a mixed background were used (21), our LckCre;Smad $4^{f / f l}$ mice were on a C57BL/6 background. Alternatively, the gastroduodenal lesions may have arisen as a consequence of an autoimmune response. For example, defective iTreg generation in Lck-Cre;Smad4fl/fl mice, and likely in GB-Cre;Smad4fl/fl mice, could plausibly engender a loss of tolerance toward gut self-antigens.

The finding of lesions in the antro-pyloric region of GBCre;Smad4fl/fl mice is not without precedent. For example, antral or antro-pyloric neoplasms have been observed in Smad4 $4^{+-}$(41, 42), Smad4E6sad (46), Tff1-/- (72), gp130 ${ }^{Y 757 F / Y 757 F}(22,73)$, gastrindeficient (56), and $M x 1$ promoter-Cre;Bmpr1a $a^{f l f l}$ (74) mice. With respect to the latter, Smad4 is a component of BMP-initiated signal transduction. Intriguingly, and in contrast to the gastric origin of polyps in GB-Cre;Smad4fl/fl mice, Lck-Cre;Smad $4^{f / / f l}$ animals developed adenomas of the proximal duodenum, immediately beyond the pyloric canal. A potential factor in the difference between these two models might be related to the fact that GB-Cre "leakiness" in hematopoietic cells leads to a gradual accumulation of Cre excisions over time within non-T cells and, importantly, macrophages. Thus, Smad4-deficient CD11 ${ }^{+}$cells could plausibly account for raised $I L-23 p 19$ and Tnfa transcript levels in GB-Cre;Smad $4 f / f l$ lesions, but not Lck-Cre;Smad4f/fl lesions, despite both models showing similar lamina propria cell IL-17A-encoding transcript increases. It is also possible that the early intrathymic deletion of Smad 4 that occurs in the Lck-Cre model might result in a qualitative difference in the $\mathrm{T}$ cell repertoire. Genetic background differences between the GB-Cre;Smad $4^{f / f l}$ (mixed genetic background) and Lck-Cre;Smad4flflf (C57BL/6 background) mice may also have been a contributing factor. The reason(s) for the difference in the anatomical location of the gastroduodenal lesions in the GB-Cre and Lck-Cre models of Smad4 deficiency thus remain nebulous.
IFN- $\gamma$ - and IL-4-encoding transcripts, indicative of Th1 and Th2 T cell responses, respectively, were not increased in the GBCre;Smad4fl/fl polyps. Rather, lamina propria IL-17A-encoding transcripts and IL-17A-expressing $\mathrm{CD}^{+} \mathrm{T}$ cells were predominant. The duodenal adenomas in Lck-Cre;Smad 4 flfl mice also demonstrated increased IL-17A-encoding transcripts. A Th17-polarizing environment within the lesions of GB-Cre;Smad 4 fl/fl mice might be predicted in view of the elevation in transcripts encoding IL-23, IL-6, IL-1 $\beta$, and TGF- $\beta$ that we observed. Importantly, both GB-Cre;Smad $4^{f l / f l}$ and Lck-Cre;Smad $4 f / f l$ lesions also expressed increased Il11 transcripts. The IL-11R $\alpha$ chain, expressed by the intestinal epithelium (75) in a complex with gp130, activates various signal transduction components, including Stat 3 transcription. The raised levels of Stat 3 and phospho-Stat 3 we observed in the GB-Cre;Smad $4^{f / f l}$ polyps were consistent with an IL-11 effect. In addition, via Stat 3 activation in the epithelium, IL-11 may also be induced in an autocrine manner, since its gene is a target of this transcription factor (76). Both human and mouse gastric cancers share the expression of several IL-11-dependent genes (23). In keeping with this, GB-Cre;Smad4fl/fl polyps contained increased levels of transcripts encoding gremlin and clusterin. We therefore propose that IL-11-induced Stat3 activation within the gut epithelium of GB-Cre;Smad $4^{f l / f l}$ and Lck-Cre;Smad $4{ }^{f l / f l}$ mice plays an important pathogenic role in polyp formation. The finding of increased transcripts encoding IL-11 (but not IL- 6 or IL-1 $\beta$ ) in antropyloric regions of 20- to 26-week-old mice suggested that IL-11 might be involved at the earliest stages of polyp development.

GB-Cre;Smad $4^{f l / f l}$ polyps also demonstrated high levels of Illb transcripts, an important result in view of a study using a transgenic line overexpressing IL- $1 \beta$ under the control of a gastric parietal cell-specific gene promoter (77). IL- $1 \beta$ in this model led to gastric hyperplasia and neoplasia associated with increased production of IL- 6 and TNF- $\alpha$. It is possible that both IL- $1 \beta$ and TNF- $\alpha$ were also promoting gastric hyperplasia via induction of IL-11, since these proinflammatory cytokines are inducers of this factor $(26$, 
62). The finding that IL-11-encoding transcripts were either not induced (in gastric explants) or only modestly induced (in stromal cells) by IL-17A suggested that if this cytokine is responsible for the IL-11 expression in the polyps, it operates via an indirect mechanism. IL-17A is able to trigger the production of TGF- $\beta 1$, IL- $1 \beta$, and TNF- $\alpha$ by macrophages, all of which are factors that stimulate IL-11 generation from intestinal subepithelial myofibroblasts and other cell types $(62,78,79)$. It is also conceivable that other Th17derived cytokines might stimulate IL-11 expression, such as IL-22, which was shown to induce IL-11 expression from colonic subepithelial myofibroblasts (80).

Lamina propria lymphocytes from GB-Cre;Smad4flfl and Lck-Cre;Smad4flfl lesions contained increased numbers of $\mathrm{IL}-17^{+} \mathrm{CD} 4^{+}$cells and IL-17A-encoding transcripts. Although TGF- $\beta$ is required for Th17 cell development, the Smad 4 component appears to be dispensable, given that our in vitro polarization studies on Lck-Cre;Smad4fl/fl $\mathrm{T}$ cells showed normal IL-17A $\mathrm{A}^{+} \mathrm{CD} 4^{+}$ $\mathrm{T}$ cell generation. Interestingly, we found that $\mathrm{FoxP} 3^{+} \mathrm{CD} 4^{+}$ $\mathrm{T}$ cell development in vitro was profoundly impaired by the lack of Smad4. Preservation of IL- $17 \mathrm{~A}^{+} \mathrm{CD} 4^{+} \mathrm{T}$ cell development with decreased FoxP3 ${ }^{+} \mathrm{CD}^{+} \mathrm{T}$ cell generation during in vitro polarization of CD4-Cre;Smad4fl/fl $\mathrm{T}$ cells has been noted previously (59). Interestingly, iTreg generation also requires $S m a d 3$, in addition to TGF- $\beta$-induced ERK and JNK activation, although the requirement for Smad3 in iTreg versus Th17 polarization appears to vary (81-83). In vivo, no defect in Foxp3 transcripts was observed in experimental animals versus controls. This may have been due to an expansion or influx of nTregs, as well as the generation of some level of iTregs $\left(\mathrm{FoxP}^{+}\right.$cell generation was not $100 \%$ curtailed even as a result of the optimized in vitro polarization conditions employed). Both of these Treg populations might be expected to accumulate in a setting of chronic T cell-mediated inflammation. The existence of an iTreg deficiency in vivo might be revealed if one were to compare FoxP3 transcript levels in our experimental mice with those in another model of gastric inflammation, instead of a non-inflamed control as we have done. The putative iTreg deficiency in the models described herein was obviously not profound enough to produce the systemic inflammatory phenotype seen in Foxp3 mutant mice $(84,85)$. Importantly, nTregs were shown to persist in the thymus, spleen, and lymph nodes of CD4Cre;Smad $4 l / f l$ mice and still harbor suppressive activity (59), further reinforcing the idea that the FoxP3 expression we observed in the lesion might be stemming, at least in part, from an nTreg population. Interestingly, nTregs (in contrast to antigen-specific iTregs) were shown to be incapable of suppressing Th17-mediated autoimmune gastritis (86). Thus, any nTregs within the polyps of the model systems described herein may be incapable of attenuating the Th17 inflammatory responses observed in the gut lesions. In summary, it is reasonable to propose that a defect in antigenspecific iTreg generation underlies the Th17-dominated inflammatory responses in the two models. Furthermore, it appears that diminished Treg function increases susceptibility to Th17 protumorigenic effects (87).

Our findings echo recent results showing that in some instances tumor-infiltrating Th17 cells can promote the growth of engrafted malignant tumors, for example, via the ability of IL-17A to elicit IL-6 from tumors and/or their associated stromal cells (61). IL- 6 induced Stat 3 activation in tumor cells, in turn contributing to their growth and survival (88). Also, elaboration of TGF- $\beta$ and IL- 6 by some tumors has been proposed to promote the polarization of activated T cells toward the Th17 phenotype (61, 89). Furthermore, and relevant to our results, a human colonic commensal organism was shown to promote tumorigenesis in Min mice as a result of a Th17-mediated response (90). In these examples, $T$ cells appeared to be acting by stimulating the growth of established malignancies, or gut epithelial cells poised for malignant transformation owing, for example, to the loss of a tumor suppressor in the Min mutant.

The gut lesions were not due to loss of Smad4 expression in the epithelium. Indeed, we found that Smad4 expression was retained within the proliferative, dysplastic epithelial cells of both experimental models. In addition, it was reported that Smad4 deficiency induced via the use of Cre expressed under the control of promoters active within the epithelium did not develop gut neoplasia (21). Thus, it is possible that gastric tumors observed in the Smad4 heterozygous mouse models (41, 42, 46, 91) were actually caused by Smad4 deficiency in hematopoietic cells, rather than the gastric epithelium. This conclusion was supported by the development of gastric and intestinal lesions in Mx1-Cre;Bmpr1aflfl mice (Mx1-Cre is an epithelial and hematopoietic-specific Cre; ref. 74), but not in villin-Cre;Bmpr $1 a^{f l / f l}$ mice (villin is an epithelial-specific Cre) $(92,93)$.

In conclusion, using two different conditional mutagenesis models to produce Smad4 deficiency in T cells, we show that a chronic increase in Th17 activity, in the absence of gastritis and likely acting via IL-11, is associated with the development of massive premalignant epithelial lesions of the gastroduodenal region.

\section{Methods}

Mice. GB-Cre;Smad4//fl mice were generated by breeding GB-Cre mice (28) (The Jackson Laboratory) on a mixed C57BL/6 $\times$ FVB background with Smad4//fl mice (94) on a mixed Black Swiss $\times 129$ background (from C.-X. Deng, NIH, Bethesda, Maryland, USA). GB-Cre;Smad4//ff; R26R-EYFP and GB-Cre;R26R-EYFP mice were generated by interbreeding GB-Cre;Smad4//fl mice with R26R-EYFP mice (49) (from F. Costantini, Columbia University, New York, New York, USA). Lck-Cre;Smad4//fl mice were generated by interbreeding Lck-Cre mice (51) (C57BL/6 background) (Taconic) with Smad4//fl mice (94) (C57BL/ 6 background; backcrossed for 9 generations). Breeding pairs carrying the GB-Cre, R26R-EYFP, and Lck-Cre transgenes were maintained in hemizygous state. Littermate controls were used for all experiments. Primers for genotyping are listed in Supplemental Table 1. Mice were housed in a viral antibody-free facility in accordance with Canadian Council on Animal Care guidelines.

Smad4 excision PCR. DNA was isolated from purified CD4+ (Stem Cell Technologies, 18752) and CD8 ${ }^{+}$(Stem Cell Technologies, 18753) T cells taken from GB-Cre;Smad $4^{f / / f l}$ splenocytes, and Smad4-excision PCR completed as published previously (21).

Histopathology and immunohistochemistry. The outer curvature of the mouse stomach was dissected, pinned to a wax block, flushed out with cold PBS, and fixed with $10 \%$ formaldehyde. Images were taken using a Zeiss M2-BIO microscope. Gut samples were processed for histology by Calgary Laboratory Services (CLS). For immunohistochemistry, sections were de-paraffinized with xylene and graded alcohols and microwaved in $10 \mathrm{mM}$ sodium citrate, $\mathrm{pH} 6.0$ (for antigen retrieval), and the anti-rabbit Peroxidase Vectastain ABC Kit (Vector Laboratories) secondary was used in combination with the following antibodies: anti-TFF1/pS2 (M-83) (1:50) and anti-PCNA (FL-261) (1:50) (Santa Cruz Biotechnology Inc., sc-28926 and sc-7907, respectively); and anti-Smad4 (C-term) antibody (Epitomics, 1676-1) (1:100). Color development was performed with DAB substrate (Sigma-Aldrich) with hematoxylin counterstaining. 
Immunofluorescence and confocal microscopy. Frozen sections were prepared by fixing stomachs in $4 \%$ paraformaldehyde for 4 hours, equilibrated in $10 \%$ sucrose for 1 hour, $30 \%$ sucrose overnight at $4{ }^{\circ} \mathrm{C}$, and again in OCT (Tissue-Tek) for 2 hours before freezing on dry ice. Sections $(10 \mu \mathrm{m})$ were baked for 2 hours at $37^{\circ} \mathrm{C}$ and rehydrated in PBS containing $0.1 \%$ Tween. After blocking in $10 \%$ goat serum/2\% BSA for 2 hours, anti-GFP ab290 (1:500) (Abcam) was added overnight, followed by Alexa Fluor 488-goat anti-rabbit IgG $(1: 1,000)$ (Molecular Probes, Invitrogen) for 2 hours. Images were taken using a Zeiss LSM-510 META confocal microscope.

Hematology studies. Blood was collected via cardiac puncture of anesthetized animals and placed in heparinized tubes (Microtainer Tubes with EDTA; BD, 365973) prior to flow cytometry (performed by CLS). IL-6 protein levels were analyzed using the Luminex 100 system (analysis performed by Eve Technologies) from serum samples.

Flow cytometry and intracellular staining. Splenocytes or lamina propria cells were suspended in 2\% FBS in PBS and incubated in the following antibodies (BD Biosciences - Pharmingen) prior to analysis on a FACScalibur equipped with CellQuest software (BD): Fc Block (anti-CD16/CD32, 2.4G2), anti-CD4-PE (L3T4), anti-CD8a-PerCP (Ly-2, 53-6.7), anti-CDllbPE, anti-CD19-PE, and anti-IL-17A-PE (for intracellular staining); antiFoxP3 antibody (eBioscience, 88-811) intracellular staining was carried out as recommended by the manufacturer. Cells were gated and quantified using FlowJo (version 3.6; TreeStar) software.

Lamina propria cell isolations. The antro-pyloric region $(\sim 1 \mathrm{~cm}$ on either side of the pyloric canal) of polyp-containing and control mice was washed in cold $\mathrm{Ca}^{2+} / \mathrm{Mg}^{2+}$-free PBS, cut into $5-\mathrm{mm}$ pieces, and washed in $5 \mathrm{mM} \mathrm{EDTA} / \mathrm{HBSS} / 10 \% \mathrm{FBS}$ solution $\left(37^{\circ} \mathrm{C} 15\right.$ minutes $\times 4$ changes) before addition of $100 \mathrm{U} / \mathrm{ml}$ collagenase II (Invitrogen, 17101-015) in RPMI $1640 / 5 \% \mathrm{FBS} / 20 \mathrm{mM}$ HEPES $\left(37^{\circ} \mathrm{C}, 1\right.$ hour). Cells were passed through a $70-\mu \mathrm{M}$ filter and used for either RNA isolation or flow cytometry. For the latter, cells were purified using a 40\%-80\% Percoll gradient and stimulated for 6 hours with $10 \mathrm{ng} / \mathrm{ml}$ PMA (Sigma-Aldrich, P8139) and $0.5 \mu \mathrm{g} / \mathrm{ml}$ ionomycin (Sigma-Aldrich, I9657) in AIM-V medium containing $3 \%$ IL-2-conditioned medium and $2 \mu \mathrm{mol} / 1 \beta$-mercaptoethanol $(\beta-\mathrm{ME})$ at $1 \times 10^{6}$ cells $/ \mathrm{ml}$.

Real-time RT-PCR and primers. For RNA isolation, gut samples were placed in RNA stabilization solution (QIAGEN), and approximately $0.1 \mathrm{~g}$ of tissue was homogenized in $1 \mathrm{ml}$ of QIAzol lysis reagent (QIAGEN), followed by addition of $200 \mu \mathrm{l}$ chloroform. After centrifugation at $15,294 \mathrm{~g}$ for 15 minutes, the upper clear layer was transferred into tubes containing $500 \mu \mathrm{l}$ ice-cold isopropanol. After centrifugation, samples were resuspended in $75 \%$ RNase-free EtOH, centrifuged again, then air-dried and resuspended in RNA-free water (OmniPur). Lamina propria cell pellets were resuspended in QIAzol lysis reagent (QIAGEN) for RNA studies. For real-time RTPCR, $2 \mu$ g of RNA was treated with DNAse ( $2 \mathrm{U}$ ) (Promega) at $37^{\circ} \mathrm{C}$ for 45 minutes and RT-PCR carried out using $10 \mathrm{mM}$ dNTPs, random primers (Roche), and Superscript II reverse transcriptase (Invitrogen) at $42^{\circ} \mathrm{C}$ for

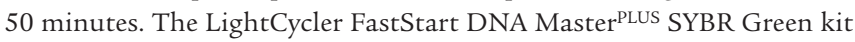
(Roche) was used for real-time PCR according to the cycling conditions recommended by the manufacturer. Data were normalized to $\beta$-actin and experimental transcripts expressed as the relative fold change in mRNA level compared with control samples. Primer sequences are listed in Supplemental Table 2 (22, 23, 95-97).

Western blot analysis. Lysates containing proteases (Roche) were prepared from splenic T cells purified by negative selection (Stem Cell Technologies, 19751), as well as from splenocytes stimulated with plate-bound anti-CD3 $(2 \mu \mathrm{g} / \mathrm{ml})$ and anti-CD28 $(2 \mu \mathrm{g} / \mathrm{ml})$ antibodies (BD Biosciences - Pharmingen) for 48 hours and expanded for 7-9 days in AIM-V medium plus $3 \%$ IL-2-conditioned medium with $2 \mu \mathrm{mol} / 1 \beta$-ME at $5 \times 10^{6}$ cells $/ \mathrm{ml}$. Lysate ( $25 \mu \mathrm{g}$ per lane) was loaded on $7.5 \%$ polyacryl- amide gels, transferred to PVDF filters, blocked with 5\% BSA, and then immunoblotted with the following antibodies (Santa Cruz Biotechnology Inc.): anti-Smad4 (B-8) sc-7966 (1:100 dilution), with an HRP-linked antibody (Cell Signaling Technology) at a 1:1,000 dilution as the secondary; anti-actin (I-19) sc-1616 (1:1,000 dilution). Antro-pyloric region lysates containing protease and PhosSTOP (Roche) and $60 \mu \mathrm{g}$ of protein were loaded per lane. PVDF filters were blocked in 5\% BSA for 1 hour and immunoblotted with the following primary antibodies (at 1:1,000): anti-phospho-Stat3 (Tyr705) (Cell Signaling Technology, 9145), antiStat3 (Cell Signaling Technology, 9139), anti-phospho-Stat1 (Tyr701) (Cell Signaling Technology, 9167), anti-Stat1 (Cell Signaling Technology, 9172), and anti-actin (I-19) (Santa Cruz Biotechnology Inc., sc-1616). An HRP-conjugated secondary antibody (Cell Signaling Technology) was used for chemiluminescence imaging.

T cell polarizations. Splenocytes from Smad4//fl or Lck-Cre;Smad $4^{f / f l}$ mice were activated with $2 \mu \mathrm{g} / \mathrm{ml}$ anti-CD3 and anti-CD28 antibodies (BD Biosciences - Pharmingen) for 48 hours in AIM-V medium containing $3 \% \mathrm{IL}-2$-conditioned medium and $2 \mu \mathrm{mol} / 1 \beta-\mathrm{ME}$ at $5 \times 10^{6}$ cells $/ \mathrm{ml}$ under iTreg-polarizing conditions $(5 \mathrm{ng} / \mathrm{ml}$ TGF- $\beta 1$ [R\&D Systems, 240-B], $10 \mu \mathrm{g} / \mathrm{ml}$ anti-IFN- $\gamma$ [BD Biosciences - Pharmingen, 554408], and $10 \mu \mathrm{g} / \mathrm{ml}$ anti-IL-4 [BD Biosciences - Pharmingen, 554432]); Th17polarizing conditions $(5 \mathrm{ng} / \mathrm{ml}$ TGF- $\beta 1,20 \mathrm{ng} / \mathrm{ml}$ IL-6 [PeproTech, 216 16 ], $50 \mathrm{ng} / \mathrm{ml} \mathrm{IL-23} \mathrm{[R \& D} \mathrm{Systems,} 1887-\mathrm{ML}$ ], and $10 \mu \mathrm{g} / \mathrm{ml}$ anti-IFN- $\gamma$ and anti-IL-4 antibodies); or non-polarizing conditions. GolgiPlug (BD, 555029) was added 10 hours prior to analysis.

Naive T cells were isolated from Smad $4^{\ell / f l}$ or Lck-Cre;Smad4//fl splenocytes using $\mathrm{CD}^{+} \mathrm{CD}_{22 \mathrm{~L}^{+}} \mathrm{T}$ Cell Isolation Kit II (Miltenyi Biotec, 130-093227) (where $98 \%-99 \% \mathrm{CD}^{+}$cells were $\mathrm{CD} 62 \mathrm{~L}^{+} \mathrm{CD} 44^{-}$) and activated with $2 \mu \mathrm{g} / \mathrm{ml}$ anti-CD3 and anti-CD28 antibodies (BD Biosciences - Pharmingen) for 2.5 days in RPMI 1640 medium containing 10\% FBS, $100 \mathrm{U} / \mathrm{ml}$ penicillin and $100 \mu \mathrm{g} / \mathrm{ml}$ streptomycin, $1 \mathrm{mM}$ sodium pyruvate, $1 \mathrm{mM}$ minimal essential medium non-essential amino acids, and $50 \mu \mathrm{M} \beta-\mathrm{ME}$ at $1 \times 10^{6}$ cells $/ \mathrm{ml}$ in 24 -well plates under iTreg-polarizing conditions ( $3 \%$ IL-2-conditioned medium, $5 \mathrm{ng} / \mathrm{ml}$ TGF- $\beta 1,10 \mu \mathrm{g} / \mathrm{ml}$ anti-IFN- $\gamma$, and $10 \mu \mathrm{g} / \mathrm{ml}$ anti-IL-4 antibodies); Th17-polarizing conditions $(2.5 \mathrm{ng} / \mathrm{ml}$ TGF- $\beta 1,20 \mathrm{ng} / \mathrm{ml} \mathrm{IL-6,} 50 \mathrm{ng} / \mathrm{ml}$ IL-23, $20 \mathrm{ng} / \mathrm{ml} \mathrm{IL-1} \beta$ [R\&D Systems, 401-ML], $10 \mu \mathrm{g} / \mathrm{ml}$ anti-IL-2 [Endogen, MM100], $10 \mu \mathrm{g} / \mathrm{ml}$ anti-IFN- $\gamma$, and $10 \mu \mathrm{g} / \mathrm{ml}$ anti-IL-4 antibodies); or non-polarizing conditions. Th17polarized cells were stimulated with $10 \mathrm{ng} / \mathrm{ml} \mathrm{PMA}$ and $0.5 \mu \mathrm{g} / \mathrm{ml}$ ionomycin for an additional 4 hours with GolgiPlug before collection for flow cytometry. Polarized $\mathrm{CD}^{+} \mathrm{T}$ cells were analyzed for either intracellular FoxP3 ${ }^{+} \mathrm{CD} 25^{+}$expression (eBioscience, 88-8111) or IL-17 expression using anti-IL-17A-PE (BD Biosciences - Pharmingen).

IL-17 stimulation on the antro-pyloric region of young mice and bone marrow stromal cell lines. The antro-pyloric regions of 7- to 10-week-old wild-type mice were bisected, and fragments from each half were cultured in microtiter plates containing RPMI 1640 medium plus 5\% FBS, $100 \mathrm{U} / \mathrm{ml}$ penicillin and $100 \mu \mathrm{g} / \mathrm{ml}$ streptomycin, $10 \mathrm{mM} \mathrm{L}$-glutamine, and $15 \mathrm{mmol} / 1 \mathrm{HEPES}$ (media from Invitrogen), with and without $2 \mu \mathrm{g} / \mathrm{ml}$ recombinant IL-17A (R\&D Systems, 421-ML-025/CF). After incubation for 24 hours, RNA was extracted from the samples for real-time RT-PCR analysis.

Mouse bone marrow stromal cell lines M2-10B4 (ATCC, CRL-1972) and D1 (ATCC, CRL-12424) were grown and expanded according to the manufacturer's protocol using the recommended medium with the addition of $100 \mathrm{U} / \mathrm{ml}$ penicillin and $100 \mu \mathrm{g} / \mathrm{ml}$ streptomycin. Cells were seeded at $5 \times 10^{5}$ to $7 \times 10^{5}$ cells/well in 6 -well plates and grown to confluency at $37^{\circ} \mathrm{C}$ and $5 \% \mathrm{CO}_{2}$. Cells were stimulated with either $100 \mathrm{ng} / \mathrm{ml}$ recombinant IL-17A (R\&D Systems, 421-ML-025/CF) or 20 ng/ml TGF- $\beta 1$ (R\&D Systems, $240-\mathrm{B})$ for 12 hours before analysis of IL-11 production by real-time RT-PCR. All experiments were completed on cells at passages (P) 3-5. 
Statistics. Statistical analyses were performed with GraphPad Prism version 4.01 (GraphPad Software) using the 2-tailed unpaired $t$ test. $P$ values less than 0.05 were considered significant.

Study approval. Studies were performed in accordance with Canadian Council on Animal Care guidelines and with ethics approval from the University of Calgary Animal Care Committee.

\section{Acknowledgments}

We thank C.-X. Deng (NIH) for providing the Smadt/fl line and F. Costantini (Columbia University) for the R26R-EYFP mice. We are also grateful to S. Tsutsui and H.A. Luchman for their expert advice and to the various technicians involved in the care of the mouse colonies and the genotyping. This work was supported by the Canadian Institutes of Health Research (CIHR). J.N. Hahn was supported by a studentship from the Multiple Sclerosis Society of Canada, and F.R. Jirik was the recipient of a Canada Research Chairs award.

Received for publication September 14, 2010, and accepted in revised form July 6, 2011.

Address correspondence to: Frank R. Jirik, 3280 Hospital Drive NW, Calgary T2N 4Z6, Alberta, Canada. Phone: 403.220.8666; Fax: 403.210.8127; E-mail: jirik@ucalgary.ca.
1. Shull MM, et al. Targeted disruption of the mouse transforming growth factor-beta 1 gene results in multifocal inflammatory disease. Nature. 1992;359(6397):693-699.

2. Kulkarni AB, et al. Transforming growth factorbeta 1 null mice. An animal model for inflammatory disorders. Am J Pathol. 1995;146(1):264-275.

3. Kulkarni AB, et al. Transforming growth factor beta 1 null mutation in mice causes excessive inflammatory response and early death. Proc Natl Acad SciUS A. 1993;90(2):770-774.

4. Liu Y, Zhang P, Li J, Kulkarni AB, Perruche S, Chen W. A critical function for TGF-beta signaling in the development of natural $\mathrm{CD} 4{ }^{+} \mathrm{CD} 25^{+} \mathrm{Foxp}^{+}$regulatory T cells. Nat Immunol. 2008;9(6):632-640.

5. Gorelik L, Flavell RA. Abrogation of TGFbeta signaling in $\mathrm{T}$ cells leads to spontaneous $\mathrm{T}$ cell differentiation and autoimmune disease. Immunity. 2000;12(2):171-181.

6. Li MO, Sanjabi S, Flavell RA. Transforming growth factor-beta controls development, homeostasis, and tolerance of $\mathrm{T}$ cells by regulatory $\mathrm{T}$ cell-dependent and -independent mechanisms. Immunity. 2006;25(3):455-471.

7. Marie JC, Liggitt D, Rudensky AY. Cellular mechanisms of fatal early-onset autoimmunity in mice with the T cell-specific targeting of transforming growth factor-beta receptor. Immunity. 2006; 25(3):441-454.

8. Bommireddy R, Doetschman T. TGFbeta1 and Treg cells: alliance for tolerance. Trends Mol Med. 2007;13(11):492-501

9. Li MO, Flavell RA. TGF-beta: a master of all T cell trades. Cell. 2008;134(3):392-404.

10. Letterio JJ. TGF-beta signaling in T cells: roles in lymphoid and epithelial neoplasia. Oncogene. 2005;24(37):5701-5712.

11. Korn T, Bettelli E, Oukka M, Kuchroo VK. IL-17 and Th17 cells. Annu Rev Immunol. 2009;27:485-517.

12. Tone Y, Furuuchi K, Kojima Y, Tykocinski ML, Greene MI, Tone M. Smad3 and NFAT cooperate to induce Foxp3 expression through its enhancer. Nat Immunol. 2008;9(2):194-202.

13. Josefowicz SZ, Rudensky A. Control of regulatory T cell lineage commitment and maintenance. Immunity. 2009;30(5):616-625.

14. Sakaguchi S, Yamaguchi T, Nomura T, Ono M. Regulatory $\mathrm{T}$ cells and immune tolerance. Cell. 2008;133(5):775-787.

15. Suzuki K, Kumanogoh A, Kikutani H. Semaphorins and their receptors in immune cell interactions. Nat Immunol. 2008;9(1):17-23.

16. Kapp JA, Bucy RP. CD8 ${ }^{+}$suppressor T cells resurrected. Hum Immunol. 2008;69(11):715-720.

17. Ivanov II, et al. The orphan nuclear receptor RORgammat directs the differentiation program of proinflammatory IL-17 $7^{+} \mathrm{T}$ helper cells. Cell. 2006;126(6):1121-1133.

18. Massagué J, Gomis RR. The logic of TGFbeta signaling. FEBS Lett. 2006;580(12):2811-2820.

19. Zhang YE. Non-Smad pathways in TGF-beta sig- naling. Cell Res. 2009;19(1):128-139.

20. Derynck R, Zhang YE. Smad-dependent and Smadindependent pathways in TGF-beta family signalling. Nature. 2003;425(6958):577-584.

21. Kim BG, et al. Smad4 signalling in T cells is required for suppression of gastrointestinal cancer. Nature. 2006;441(7096):1015-1019.

22. Ernst M, et al. STAT3 and STAT1 mediate IL-11dependent and inflammation-associated gastric tumorigenesis in gp130 receptor mutant mice. J Clin Invest. 2008;118(5):1727-1738.

23. Howlett $M$, et al. The interleukin- 6 family cytokine interleukin-11 regulates homeostatic epithelial cell turnover and promotes gastric tumor development. Gastroenterology. 2009;136(3):967-977.

24. Nakayama T, et al. Expression of interleukin-11 (IL-11) and IL-11 receptor alpha in human gastric carcinoma and IL-11 upregulates the invasive activity of human gastric carcinoma cells. Int J Oncol. 2007;30(4):825-833.

25. Jackson CB, et al. Augmented gp130-mediated cytokine signalling accompanies human gastric cancer progression. J Pathol. 2007;213(2):140-151.

26. Du X, Williams DA. Interleukin-11: review of molecular, cell biology, and clinical use. Blood. 1997;89(11):3897-3908

27. Johnson TA, Tsutsui S, Jirik FR. Antigen-induced Pten gene deletion in T cells exacerbates neuropathology in experimental autoimmune encephalomyelitis. Am J Pathol. 2008;172(4):980-992.

28. Jacob J, Baltimore D. Modelling T-cell memory by genetic marking of memory $\mathrm{T}$ cells in vivo. Nature. 1999;399(6736):593-597.

29. Maris CH, Miller JD, Altman JD, Jacob J. A transgenic mouse model genetically tags all activated CD8 T cells. J Immunol. 2003;171(5):2393-2401.

30. Cai SF, et al. Differential expression of granzyme B and $\mathrm{C}$ in murine cytotoxic lymphocytes. J Immunol. 2009;182(10):6287-6297.

31. Gondek DC, Lu LF, Quezada SA, Sakaguchi S, Noelle RJ. Cutting edge: contact-mediated suppression by $\mathrm{CD} 4{ }^{+} \mathrm{CD} 25^{+}$regulatory cells involves a granzyme B-dependent, perforin-independent mechanism. J Immunol. 2005;174(4):1783-1786.

32. Grossman WJ, Verbsky JW, Tollefsen BL, Kemper C, Atkinson JP, Ley TJ. Differential expression of granzymes A and B in human cytotoxic lymphocyte subsets and $\mathrm{T}$ regulatory cells. Blood. 2004;104(9):2840-2848.

33. Shevach EM, DiPaolo RA, Andersson J, Zhao DM, Stephens GL, Thornton AM. The lifestyle of naturally occurring $\mathrm{CD}^{+} \mathrm{CD}_{2} 5^{+} \mathrm{Foxp}^{+}$regulatory $\mathrm{T}$ cells. Immunol Rev. 2006;212:60-73.

34. Cao X, et al. Granzyme B and perforin are important for regulatory $\mathrm{T}$ cell-mediated suppression of tumor clearance. Immunity. 2007;27(4):635-646.

35. Suzuki M, Konya C, Goronzy JJ, Weyand CM. Inhibitory $\mathrm{CD}^{+} \mathrm{T}$ cells in autoimmune disease. Hum Immunol. 2008;69(11):781-789.

36. Kebir H, et al. Human TH17 lymphocytes promote blood-brain barrier disruption and central nervous system inflammation. Nat Med. 2007; 13(10):1173-1175.

37. Oberhuber G, Stolte M. Gastric polyps: an update of their pathology and biological significance. Virchows Arch. 2000;437(6):581-590.

38. Miyaki M, Kuroki T. Role of Smad4 (DPC4) inactivation in human cancer. Biochem Biophys Res Commun. 2003;306(4):799-804.

39. Powell SM, Harper JC, Hamilton SR, Robinson CR, Cummings OW. Inactivation of Smad4 in gastric carcinomas. Cancer Res. 1997;57(19):4221-4224.

40. Schutte M, et al. DPC4 gene in various tumor types. Cancer Res. 1996;56(11):2527-2530.

41. Xu X, et al. Haploid loss of the tumor suppressor Smad4/Dpc4 initiates gastric polyposis and cancer in mice. Oncogene. 2000;19(15):1868-1874.

42. Takaku K, Miyoshi H, Matsunaga A, Oshima M, Sasaki N, Taketo MM. Gastric and duodenal polyps in Smad4 (Dpc4) knockout mice. Cancer Res. 1999;59(24):6113-6117.

43. Alberici P, et al. Smad4 haploinsufficiency in mouse models for intestinal cancer. Oncogene. 2006;25(13):1841-1851.

44. Karlsson G, et al. Smad4 is critical for selfrenewal of hematopoietic stem cells. J Exp Med. 2007;204(3):467-474.

45. Pan D, et al. Normal erythropoiesis but severe polyposis and bleeding anemia in Smad4-deficient mice. Blood. 2007;110(8):3049-3055.

46. Hohenstein P, et al. Serrated adenomas and mixed polyposis caused by a splice acceptor deletion in the mouse Smad4 gene. Genes Chromosomes Cancer. 2003;36(3):273-282.

47. Howe JR, et al. Mutations in the SMAD4/ DPC4 gene in juvenile polyposis. Science. 1998; 280(5366):1086-1088.

48. Schreibman IR, Baker M, Amos C, McGarrity TJ. The hamartomatous polyposis syndromes: a clinical and molecular review. Am J Gastroenterol. 2005;100(2):476-490.

49. Srinivas $S$, et al. Cre reporter strains produced by targeted insertion of EYFP and ECFP into the ROSA26 locus. BMC Dev Biol. 2001;1:4.

50. Thomas DA, Massagué J. TGF-beta directly targets cytotoxic $\mathrm{T}$ cell functions during tumor evasion of immune surveillance. Cancer Cell. 2005;8(5):369-380.

51. Lee PP, et al. A critical role for Dnmt1 and DNA methylation in $\mathrm{T}$ cell development, function, and survival. Immunity. 2001;15(5):763-774.

52. Kim JY, et al. Smad4 expression in gastric adenoma and adenocarcinoma: frequent loss of expression in diffuse type of gastric adenocarcinoma. Histol Histopathol. 2005;20(2):543-549.

53. Li Q, Karam SM, Coerver KA, Matzuk MM, Gordon JI. Stimulation of activin receptor II signaling pathways inhibits differentiation of multiple gastric epithelial lineages. Mol Endocrinol. 1998;12(2):181-192.

54. Fukamachi H, Ito K. Growth regulation of gastric epithelial cells by Runx3. Oncogene. 2004; 23(24):4330-4335.

55. Tomasetto C, Rio MC. Pleiotropic effects of Tre- 
foil Factor 1 deficiency. Cell Mol Life Sci. 2005; 62(24):2916-2920.

56. Zavros Y, et al. Chronic gastritis in the hypochlorhydric gastrin-deficient mouse progresses to adenocarcinoma. Oncogene. 2005;24(14):2354-2366.

57. Judd LM, Bredin K, Kalantzis A, Jenkins BJ, Ernst M, Giraud AS. STAT3 activation regulates growth, inflammation, and vascularization in a mouse model of gastric tumorigenesis. Gastroenterology. 2006;131(4):1073-1085.

58. Yang J, Stark GR. Roles of unphosphorylated STATs in signaling. Cell Res. 2008;18(4):443-451.

59. Yang XO, et al. Molecular antagonism and plasticity of regulatory and inflammatory $\mathrm{T}$ cell programs. Immunity. 2008;29(1):44-56.

60. Yang YC. Interleukin 11: an overview. Stem Cells. 1993;11(6):474-486.

61. Wang L, Yi T, Kortylewski M, Pardoll DM, Zeng D, Yu H. IL-17 can promote tumor growth through an IL-6-Stat3 signaling pathway. J Exp Med. 2009; 206(7):1457-1464.

62. Bamba S, Andoh A, Yasui H, Makino J, Kim S, Fujiyama Y. Regulation of IL-11 expression in intestinal myofibroblasts: role of c-Jun AP-1- and MAPKdependent pathways. Am J Physiol Gastrointest Liver Physiol. 2003;285(3):G529-G538.

63. Sadlack B, Merz H, Schorle H, Schimpl A, Feller AC, Horak I. Ulcerative colitis-like disease in mice with a disrupted interleukin-2 gene. Cell. 1993;75(2):253-261.

64. Sellon RK, et al. Resident enteric bacteria are necessary for development of spontaneous colitis and immune system activation in interleukin-10-deficient mice. Infect Immun. 1998;66(11):5224-5231.

65. Dianda L, Hanby AM, Wright NA, Sebesteny A, Hayday AC, Owen MJ. T cell receptor-alpha beta-deficient mice fail to develop colitis in the absence of a microbial environment. Am J Pathol. 1997;150(1):91-97.

66. Atarashi $\mathrm{K}$, et al. ATP drives lamina propria $\mathrm{T}(\mathrm{H}) 17$ cell differentiation. Nature. 2008;455(7214):808-812.

67. Monteleone I, Pallone F, Monteleone G. Interleukin-23 and Th17 cells in the control of gut inflammation. Mediators Inflamm. 2009;2009:297645.

68. Brand S. Crohn's disease: Th1, Th17 or both? The change of a paradigm: new immunological and genetic insights implicate Th17 cells in the pathogenesis of Crohn's disease. Gut. 2009;58(8):1152-1167.

69. Ivanov II, et al. Specific microbiota direct the differentiation of IL-17-producing T-helper cells in the mucosa of the small intestine. Cell Host Microbe. 2008;4(4):337-349.
70. Goto K, et al. Epidemiology of Helicobacter infection in wild rodents in the Xinjiang-Uygur autonomous region of China. Curr Microbiol. 2004;49(3):221-223.

71. Elso CM, et al. Heightened susceptibility to chronic gastritis, hyperplasia and metaplasia in Kcnq1 mutant mice. Hum Mol Genet. 2004;13(22):2813-2821.

72. Lefebvre $\mathrm{O}$, et al. Gastric mucosa abnormalities and tumorigenesis in mice lacking the pS2 trefoil protein. Science. 1996;274(5285):259-262.

73. Tebbutt NC, et al. Reciprocal regulation of gastrointestinal homeostasis by SHP2 and STAT-mediated trefoil gene activation in gp130 mutant mice. Nat Med. 2002;8(10):1089-1097.

74. Bleuming SA, et al. Bone morphogenetic protein signaling suppresses tumorigenesis at gastric epithelial transition zones in mice. Cancer Res. 2007;67(17):8149-8155.

75. Andoh A, Bamba S, Brittan M, Fujiyama Y, Wright NA. Role of intestinal subepithelial myofibroblasts in inflammation and regenerative response in the gut. Pharmacol Ther. 2007;114(1):94-106.

76. Merchant JL. What lurks beneath: IL-11, via Stat3, promotes inflammation-associated gastric tumorigenesis. J Clin Invest. 2008;118(5):1628-1631.

77. Tu S, et al. Overexpression of interleukin-1beta induces gastric inflammation and cancer and mobilizes myeloid-derived suppressor cells in mice. Cancer Cell. 2008;14(5):408-419.

78. Kang Y, et al. Breast cancer bone metastasis mediated by the Smad tumor suppressor pathway. Proc Natl Acad Sci U S A. 2005;102(39):13909-13914.

79. Tang W, Yang L, Yang YC, Leng SX, Elias JA. Transforming growth factor-beta stimulates interleukin-11 transcription via complex activating protein-1-dependent pathways. J Biol Chem. 1998; 273(10):5506-5513

80. Andoh A, et al. Interleukin-22, a member of the IL10 subfamily, induces inflammatory responses in colonic subepithelial myofibroblasts. Gastroenterology. 2005;129(3):969-984

81. Lu L, et al. Role of SMAD and non-SMAD signals in the development of Th17 and regulatory T cells. J Immunol. 2010;184(8):4295-4306.

82. Martinez GJ, et al. Smad3 differentially regulates the induction of regulatory and inflammatory $\mathrm{T}$ cell differentiation. J Biol Chem. 2009;284(51):35283-35286.

83. Jana S, et al. The role of NF-kappaB and Smad3 in TGF-beta-mediated Foxp3 expression. Eur J Immunol. 2009;39(9):2571-2583.

84. Brunkow ME, et al. Disruption of a new forkhead/ winged-helix protein, scurfin, results in the fatal lymphoproliferative disorder of the scurfy mouse. Nat Genet. 2001;27(1):68-73.

85. Khattri R, Cox T, Yasayko SA, Ramsdell F. An essential role for Scurfin in $\mathrm{CD} 4{ }^{+} \mathrm{CD} 25^{+} \mathrm{T}$ regulatory cells. Nat Immunol. 2003;4(4):337-342.

86. Huter EN, Stummvoll GH, DiPaolo RJ, Glass DD, Shevach EM. Pre-differentiated Th1 and Th17 effector T cells in autoimmune gastritis: Ag-specific regulatory $\mathrm{T}$ cells are more potent suppressors than polyclonal regulatory T cells. Int Immunopharmacol. 2009;9(5):540-545.

87. Erdman SE, et al. Unifying roles for regulatory $\mathrm{T}$ cells and inflammation in cancer. Int J Cancer. 2010;126(7):1651-1665.

88. Bromberg J, Wang TC. Inflammation and cancer: IL- 6 and STAT3 complete the link. Cancer Cell. 2009;15(2):79-80.

89. Nam JS, et al. Transforming growth factor beta subverts the immune system into directly promoting tumor growth through interleukin-17. Cancer Res. 2008;68(10):3915-3923.

90. Wu S, et al. A human colonic commensal promotes colon tumorigenesis via activation of T helper type 17 T cell responses. Nat Med. 2009;15(9):1016-1022.

91. Chen Y, Yee D, Magnuson T. A novel mouse Smad4 mutation reduces protein stability and wild-type protein levels. Mamm Genome. 2006; 17(3):211-219.

92. Auclair BA, Benoit YD, Rivard N, Mishina Y, Perreault $\mathrm{N}$. Bone morphogenetic protein signaling is essential for terminal differentiation of the intestinal secretory cell lineage. Gastroenterology. 2007;133(3):887-896

93. Hardwick JC, Kodach LL, Offerhaus GJ, van den Brink GR. Bone morphogenetic protein signalling in colorectal cancer. Nat Rev Cancer. 2008; $8(10): 806-812$

94. Yang X, Li C, Herrera PL, Deng CX. Generation of Smad4/Dpc4 conditional knockout mice. Genesis. 2002;32(2):80-81.

95. Martin-Saavedra FM, et al. Beta-interferon unbalances the peripheral $\mathrm{T}$ cell proinflammatory response in experimental autoimmune encephalomyelitis. Mol Immunol. 2007;44(14):3597-3607.

96. Nagasaka S, Iwasaki T, Okano T, Chiba J. Antigenspecific IL-23/17 pathway activation by murine semi-mature DC-like cells. Biochem Biophys Res Commun. 2009;387(1):52-57.

97. Overbergh L, Valckx D, Waer M, Mathieu C. Quantification of murine cytokine mRNAs using real time quantitative reverse transcriptase PCR. Cytokine. 1999;11(4):305-312. 